\title{
Extending the area of investigation of fine versus coarse quartz optical ages from the Lower Danube to the Carpathian Basin
}

Timar-Gabor, Alida; Constantin, Daniela; Markovi, S.B.; Jain, Mayank

Published in:

Quaternary International

Link to article, DOI:

10.1016/j.quaint.2014.09.065

Publication date:

2015

Document Version

Peer reviewed version

Link back to DTU Orbit

Citation (APA):

Timar-Gabor, A., Constantin, D., Markovi, S. B., \& Jain, M. (2015). Extending the area of investigation of fine versus coarse quartz optical ages from the Lower Danube to the Carpathian Basin. Quaternary International, 388, 168-176. https://doi.org/10.1016/j.quaint.2014.09.065

\section{General rights}

Copyright and moral rights for the publications made accessible in the public portal are retained by the authors and/or other copyright owners and it is a condition of accessing publications that users recognise and abide by the legal requirements associated with these rights.

- Users may download and print one copy of any publication from the public portal for the purpose of private study or research.

- You may not further distribute the material or use it for any profit-making activity or commercial gain

- You may freely distribute the URL identifying the publication in the public portal 


\title{
Extending the area of investigation of fine versus coarse quartz optical ages from the Lower Danube to the Carpathian Basin
}

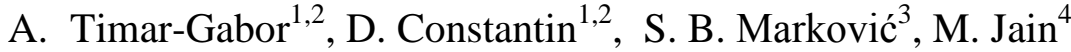 \\ ${ }^{I}$ Faculty of Environmental Science and Engineering, Babeş-Bolyai University, \\ Fântânele 30, 400294 ClujNapoca, Romania \\ ${ }^{2}$ Interdisciplinary Research Institute on Bio-Nano-Science of Babeş-Bolyai University, \\ TreboniuLaurean 42, 400271 Cluj-Napoca, Romania \\ ${ }^{3}$ Chair of Physical Geography, Faculty of Sciences, University of Novi Sad, 21000, Novi Sad, Serbia \\ ${ }^{4}$ Center for Nuclear Technologies, Technical University of Denmark, Ris $\phi$ campus, DK 4000 Roskilde, Denmark \\ * Corresponding author; Email: alida.timar@ubbcluj.ro
}

\section{Abstract}

Despite the general satisfactory performance of quartz in the single aliquot regeneration protocol (SAR), previous optically stimulated luminescence (OSL) dating studies of key loess sections in Romania, Lower Danube region, revealed a disturbing disagreement among the ages obtained on fine $(4-11 \mu \mathrm{m})$ grains and coarse $(63-90 \mu \mathrm{m})$ grains respectively. The current study aims at expanding these investigations, both by extending the area of study from the Lower Danube Basin to the Carpathian Basin and by applying time-resolved optically stimulated luminescence (TR-OSL) on quartz, in order to gain further insights into the above mentioned behaviour. The samples from Orlovat loess paleosol section (Vojvodina, Serbia) showed a similar behaviour to that previously reported on Romanian loess. A marked difference between the dose saturation characteristics of fine and coarse quartz OSL signals is observed for both continuous wave (CWOSL) and pulsed OSL (POSL), where the dose response (up to $1000 \mathrm{~Gy}$ ) is well described by a sum of two saturating exponential functions. TR-OSL measurements show one single, characteristic quartz lifetime for both natural as well as regenerative signals in the entire dose range investigated. A general disagreement between the ages obtained on the two grain sizes for samples with equivalent doses higher than about $100 \mathrm{~Gy}$ is reported as in the case of Romanian loess, inferring that the age discrepancy between the two grain sizes might be more widespread than previously thought.

Keywords: quartz, loess, single aliquot regeneration (SAR) protocol, dose response, timeresolved optically stimulated luminescence (TR-OSL). 


\section{Introduction}

The loess paleosol sequences of the Carpathian Basin and Lower Danube region (Serbia, Romania, Bulgaria) are thought to represent the most continuous and high resolution archives of regional climate and environmental change during the Late and Middle Pleistocene, (Fitzsimmons et al., 2012), and a link between European and Asian loess deposits (Marković et al., 2012). Their significance however, can only be fully understood only once a reliable and absolute chronology is available. Technological developments in the past years have resulted in significant improvements in the achievable precision and accuracy using luminescence dating; it is now considered one of the most important chronometric methods in the study of the late Quaternary (Wintle, 2008). However, dating applications recently performed on Romanian loess by the application of optically stimulated luminescence on quartz lead to unexpected results.

A first study has reported optically stimulated luminescence (OSL) ages for the loess sequence near Mircea-Vodă (Dobrogea, SE Romania) using silt-sized $(4-11 \mu \mathrm{m})$ quartz as dosimeter (Timar et al., 2010). An internally consistent set of optical ages was obtained; however, a comparison of these ages with a magnetic time-depth model based on magnetic susceptibility measurements suggested a systematic underestimation beyond the penultimate glacial period (the SAR OSL ages of the three samples below the S1 soil were interpreted as age underestimates). Interestingly, the OSL signals from these samples did not indicate any odd characteristics: the dominance of the fast component in the OSL signals was indicated by the decay shape of the CW-OSL and LM-OSL signals; and the samples passed the procedural tests of the single-aliquot regenerative-dose (SAR) protocol (i.e. recycling ratio, recuperation, dose recovery and preheat plateau tests) indicating that the protocol should provide reliable results, while the natural signals were found well below the saturation region of the laboratory dose response.

It was concluded that optical dating of fine-grained quartz can be used to establish a reliable chronology for Romanian loess up to $\sim 70$ ka corresponding to an equivalent dose of $~ 200 \mathrm{~Gy}$. Such a behaviour is consistent with results from old (>70 ka) Chinese loess (Buylaert et al., 2007), and with the more general suggestion that SAR may underestimate the true age in the older age range (Murray et al., 2007; Lowick et al. 2010a,b, 2011). Thus, apparently reliable OSL laboratory measurement procedure does not necessarily guarantee an accurate 
determination of the true burial dose. A subsequent study of coarse-grained (63-90 $\mu \mathrm{m})$ quartz extracted from the same section (Timar-Gabor et al., 2011) revealed that equivalent doses obtained for coarse quartz grains were systematically larger than those for the fine grains; the observed difference was too high to be explained by partial bleaching or microdosimetric effects. Furthermore, both quartz fractions passed the procedural tests of the single-aliquot regenerativedose (SAR) protocol and yielded an internally consistent set of optical ages.

Timar-Gabor et al. (2012) investigated into the shape of the dose response curve for the two grain size fractions in the high dose region of 5-10 kGy; they observed an age discrepancy in the Mostiştea section (Romanian plain) similar to that in the Mircea-Vodă. Work on Costineşti section (Dobrogea, SE Romania) (Constantin et al., 2014) again confirms the same trend. From the study of Timar-Gabor et al. (2012) two additional issues of general importance to the SAR protocol emerged. Firstly the natural signal of an infinitely old sample was found not to be in saturation, perhaps implying that the dose response measured in the laboratory may not simulate trapped charge growth during burial; this aspect was further investigated by Timar-Gabor and Wintle (2013). Secondly, it was observed that the dose response curve for coarse grains (63-90 $\mu \mathrm{m})$ is very different from fine grains $(4-11 \mu \mathrm{m})$, the latter saturating at much higher doses. A similar observation has also been made by Constantin et al. (2012) where dose response curves of fine grains $(4-11 \mu \mathrm{m})$ and coarse grains of different sizes (63-90, 90-125, 125-180 $\mu \mathrm{m})$ were compared for Căciulăteşti site (SW Romania). This different dose response pattern was also reported for quartz extracted from loess in Western Europe by Kreutzer et al. (2012). This is mostly intriguing in correlation to the fact that the fine fraction underestimates the true ages earlier than the coarse fraction does. Also, it is important to note that the values obtained for the saturation characteristics for the fine quartz fraction are very similar to the values reported by other international studies (e.g. Lowick et al., 2010b) in their work on fine material, while the saturation characteristic doses obtained in this study for coarse grained quartz are close to the values previously reported by others on coarse material from other locations (e.g. Murray et al., 2007; Pawley et al., 2010).

In a geochemical characterisation study performed by Buggle et al. (2008) it was confirmed that both Serbian and Dobrudjan loess have a major component derived from Danube alluvium. As second material sources, loess in the Dobrudja region showed a significant contribution of a second loess source, probably the glaciofluvial sediments of the Ukraine, to which variable 
contributions from local sand dune fields can be considered. Although the different origin of the sedimentary grains in loess should not justify the difference in equivalent doses that leads to a systematic age offset between the coarse and fine grains ages, it should be taken into consideration whether the different properties of fine and coarse grains can be due to their possible different origin. In the present study we are extending the investigated area by analysing whether the above mentioned finds are more than a local feature of the eastern part of the Lower Danube basin or do apply to the Carpathian Basin loess as well.

\section{Samples, instrumentation and measurement protocol}

The present work focuses on eight loess samples collected form a loess-paleosol sequence exposed in a brickyard at the village of Orlovat, located in the Tamiš loess plateau (Figure 1). Out of these, samples ORL-8 to ORL-4 have been collected from L1 unit, samples ORL 3 and ORL 2 have been sampled form S1 unit, while sample ORL 1 belongs to L2 unit, thus a total age span of more than $130 \mathrm{ka}$ being covered (Figure 2). The importance of the Orlovat section as a key archive for the late Pleistocene paleoclimate and paleoenvironment of the southeastern part of the Carpathian Basin has been emphasized by previous multi-proxi studies (Marković et al., 2014; Lukić et al. 2014) to which the reader is referred to for more information.

OSL dating of coarse $(63-90 \mu \mathrm{m})$ quartz was also documented in Marković et al. (2014). Fine quartz extraction followed the conventional procedures described in our previous studies (Timar et al. 2010; Timar-Gabor et al. 2011; Constantin et al., 2014). All continuous wave optically stimulated luminescence measurements (CW-OSL) were made in the Cluj Luminescence Dating Laboratory with a Risø TL/OSL DA-20 reader equipped with blue light emitting diodes (LEDs) emitting at $470 \pm 30 \mathrm{~nm}$ and IR LEDs emitting at $875 \pm 80 \mathrm{~nm}$; luminescence signals were observed through a $7.5 \mathrm{~mm}$ thick Hoya U-340 UV filter. Irradiations have been carried out using a ${ }^{90} \mathrm{Sr}^{90} \mathrm{Y}$ beta source, calibrated using fine and coarse quartz supplied by Ris $\varnothing$ National Laboratory. The dose rate, for the time of measurement, determined for coarse grains mounted on stainless steel disks was $0.147 \mathrm{~Gy} / \mathrm{s}$, while the dose rate for fine grains deposited on aluminium disks amounted to $0.118 \mathrm{~Gy} / \mathrm{s}$. Details of the measurement apparatus can be found in Thomsen et al. (2006). The OSL signal was collected in time intervals of $0.154 \mathrm{~s}$. All samples have been analysed in a SAR protocol (Murray and Wintle, 2000, 2003). The OSL signal used 
for analysis was that obtained for the first $0.308 \mathrm{~s}$ of the decay curve minus a background derived from the signal measured between 2.464 and $3.080 \mathrm{~s}$, as had been used in previous studies on Romanian loess (Timar et al., 2010; Timar-Gabor et al., 2011; Timar-Gabor et al., 2012; Timar-Gabor and Wintle, 2013) and the recommendations of Cunningham and Wallinga, (2010). Natural and regenerated signals were measured after a preheat of $10 \mathrm{~s}$ at $220^{\circ} \mathrm{C}$ unless otherwise stated; the response to the test dose (16 Gy) was measured after a cutheat to $180^{\circ} \mathrm{C}$. The value of the test dose was kept constant through all measurements for both grain sizes of quartz. After the measurement of the response to the test dose, a high-temperature bleach was performed by stimulating with the blue diodes for $40 \mathrm{~s}$ at $280^{\circ} \mathrm{C}$ (Murray and Wintle, 2003). Time resolved optically stimulated luminescence (TR-OSL) experiments have been carried out in Risø National Laboratory on a Risø TL/OSL-20 (their reader V) equipped with an integrated pulsing option to control the LEDs, and a Photon Timer attachment to record the TR-OSL described in detail in Lapp et al. (2009). All TR-OSL experiments have been carried out using the same measurement parameters previously used in CW-OSL. For stimulating and recording the TR-OSL signals the total measurement time was set to $100 \mathrm{~s}$, with a pulse period of $500 \mu \mathrm{s}$ consisting of an on time of $50 \mu \mathrm{s}$ and an off time of $450 \mu \mathrm{s}$; this can be translated to a net stimulation period equivalent to $10 \mathrm{~s}$ in CW-OSL. A total of 500 data points were used for data collection in pulsed stimulation out of which the first and the last five channels were dead channels. Measurement of dose response curves using pulsed optically stimulated luminescence measurements have been specially designed in order to reproduce the CW-OSL measurements conditions as closely as possible, and to minimise any possible feldspar contamination to quartz, by: (i) selection of an on time of $50 \mu \mathrm{s}$ (ii) gating the photomultiplier for counting only during the off period; (iii) ignoring the first $4 \mu$ s during the off time in TR-OSL OSL data analysis (Ankjærgaard et al., 2010).

The specific activities of radionuclides of interest for dose rate determination $\left({ }^{238} \mathrm{U}\right.$-series, ${ }^{232} \mathrm{Th}$ series and ${ }^{40} \mathrm{~K}$ ) were obtained through high-resolution gamma spectrometry using an ORTEC hyperpure germanium detector having the following characteristics: active volume of $181 \mathrm{~cm}^{3}$, $0.878 \mathrm{keV}$ FWHM at $5.9 \mathrm{keV}, 1.92 \mathrm{keV}$ FWHM and $34.2 \%$ relative efficiency at $1332.5 \mathrm{keV}$, calibrated in efficiency using International Atomic Energy Agency standards.

\section{Continuous wave optically stimulated luminescence investigations and age results}


161 All samples investigated displayed bright and rapidly decaying OSL signals. Dose recovery tests have been carried out on every sample according to the methodology outlined by Murray and Wintle (2003). The given dose was chosen to be as close as possible to the estimated equivalent dose and at least three aliquots have been used for each sample. Figure 3 presents the results obtained for fine grains (panel a)) alongside with the results obtained on coarse grains (panel b)) previously presented by Marković et al. (2014). It can be noted that for all samples laboratory given doses can be measured both accurately and precisely, although a slight trend towards overestimation of the given dose can be observed in both grain size fractions. Equivalent doses have been measured using at least 12 aliquots in the case of coarse $(63-90 \mu \mathrm{m})$ quartz except sample ORL 2 where analysis have been carried out on eight aliquots due to lack of material. For fine $(4-11 \mu \mathrm{m})$ quartz, which show more reproducible results at least 7 aliquots

172 have been used. Table 1 summarizes all data relevant to equivalent dose measurement, while 173 Table 2 presents the relevant information for age determination. It can be noted that both grain 174 size fractions show a general compliance with the prerequisites for the SAR protocol, such as recycling, IR depletion, recuperation and dose recovery. The age discrepancy between coarse and fine grains previously reported for Romanian loess, is also observed for the samples investigated in this study, except for the youngest two samples (ORL 8 and ORL7). As in the case of our previous investigations, the age difference can be attributed to the difference in equivalent doses; contrary to the dosimetric expectation, the values derived from the coarse quartz are systematically higher than the values obtained on fine quartz. One possible cause of concern is related to a thermal instability of the OSL signal sampled from the fine fraction. This could be caused either by contamination of the signal with an unstable medium OSL component (see e.g. Choi et al., 2003; Li and Li, 2006; Steffen et al., 2009), or by a thermal instability of the fast OSL component itself (Fan et al., 2011). This has been tested using preheat plateau tests (Figure 4a) and high resolution pulse annealing experiments for both natural and regenerated signals (Figure 4b). There is no dependency of the measured equivalent dose on preheat temperature and the three datasets obtained in pulse anneal experiments (natural, regenerated and calibration quartz) suggest that the stability of the fast component for both grain sizes is the same, therefore, the long term stability of the signal should not be a problem. 
190 One of the major differences in the behaviour of fine and coarse quartz grains previously 191 reported for Romanian loess was observed in the different dose response saturation 192 characteristics. We have examined this on the Orlovat samples by constructing dose response 193 curves up to 1000 Gy using four different samples and at least three aliquots for each sample.

194 The results are presented in Figure 5. As in the case of Romanian loess it can be observed that: 195 (i) there is little scatter between aliquots of the same sample; (ii) the growth pattern for the same 196 grain size is not age dependent; (iii) the growth pattern can be fitted well only with a sum of two 197 exponential functions, (iv) although the dose response of the two grain sizes investigated has the 198 same shape up to approximately $100 \mathrm{~Gy}$, there is a marked difference between the fine and the 199 coarse grain's saturation characteristics, with coarse grains saturating at much lower doses than 200 the fine grains.

201 It is also interesting to note that samples ORL 7 and ORL 8 for which the OSL ages were found 202 in agreement have both equivalent doses lower than $100 \mathrm{~Gy}$, thus these values are in the region 203 where the first exponential component is below saturation and where the dose response curves of 204 the two grain sizes are consistent with each other. The same results have been obtained on a 205 recent study on Romanian loess located in the southern RomanianPlain, in S-W Romania 206 (Constantin et al., online published) where quartz ages obtained on fine and coarse quartz for 207 the uppermost two young samples (ages about $11 \mathrm{ka}$, and $20 \mathrm{ka}$ respectively) were found in 208 agreement.

209

\section{Time resolved optically stimulated investigations}

211

212 In pulsed stimulation (POSL) the incident photon flux is delivered with pulses with a certain 213 pulse width, which is generically called the on-time. The stimulation pulses are separated by a 214 period called off-time during which it is possible to measure the decay of the luminescence 215 signal generated by the preceding stimulation pulse. The decay of this signal, registered as 216 function of time on a nano to microscale range is called time resolved luminescence (TR-OSL). 217 The shape of TR-OSL is mineral and trap dependent, and therefore it can be used as a powerful 218 instrumental method for isolating quartz signals in mixed quartz-feldspars samples (Denby et al., 219 2006; Thomsen et al., 2008). Thus, by the application of pulsed stimulation one can confirm 220 whether the growth of signal with dose observed in continuous wave stimulation is indeed a 
221 characteristic of quartz, or is an experimental artefact caused by feldspar contamination that

222 might have not been detected through IR depletion ratio tests.

223 On the other hand, the examination of the lifetimes derived from time resolved optically 224 stimulated luminescence signals can give insights on the recombination processes in quartz. One 225 possible mechanism for the different saturation characteristics observed for the signal dose response of the two grain sizes could be competition between different recombination centres.

227 This competition may in turn be dependent on the different origins of fine and coarse quartz 228 grains. This effect was investigated on sample ORL 4 on fine and coarse grains using TR-OSL.

229 A typical quartz time resolved OSL curve recorded both during on and off time is presented in 230 Figure 6.

231 Photon arrival time distributions have been recorded for natural signals as well as for different 232 laboratory given doses ranging from 19 to $969 \mathrm{~Gy}$, using a similar SAR measurement protocol as 233 in the case of continuous wave experiments. During these experiments the photomultiplier was 234 gated for counting only during the off period. The results obtained on one representative aliquot 235 of fine grains are depicted in Figure 7a. It can be noted that during off time the signals display a slow decay, typical for quartz. It can be seen as well that a prior IR exposure of 100 s at $125{ }^{\circ} \mathrm{C}$ 237 does not influence the shape of the signal. This is further confirmation that the continuing growth 238 of the signals up to very high doses noted in CW-OSL studies cannot be attributed to feldspar contamination. Similar results have been obtained on coarse quartz grains (data not shown here). The off-time photon-arrival-time distribution for all investigated doses can be fitted adequately with a single exponential function (see an example in Figure 7b).

243 The dose response curves constructed using pulsed OSL follow the same pattern as in the case of continuous wave OSL experiments (Figure 8a) showing beyond doubt that the discrepancy observed between coarse and fine grains is inherent in quartz OSL, and not due to some contaminant. Moreover, the equivalent doses obtained using pulsed OSL on four aliquots (ORL 4 fine $\mathrm{De}=171 \pm 9 \mathrm{~Gy}$; ORL 4 coarse $\mathrm{De}=170 \pm 16 \mathrm{~Gy}$ ) are in good agreement with the CW247 OSL equivalent doses (see Table 1).

248 The average lifetime values for natural and regenerated signals obtained on coarse and fine 249 grains are depicted in Figure 8b (four aliquots were used for each point). It can be observed that 250 the values range in the typical interval for quartz (36.5-38.5 $\mu \mathrm{s})$ for a stimulation temperature of $251125^{\circ} \mathrm{C}$ (e.g. Chithambo, 2003; Ankjærgaard et al., 2010-figure 1; Pagonis et al., 2011) and 
there is no marked dependence of lifetime as function of given dose, in contrast to the finds on certain samples of Chithambo et al. (2008). Due to the strong thermal quenching observed for this emission, and the satisfactory application of the Mott-Seitz model to explain TR-OSL data (Pagonis et al., 2010) we can assume the likely possibility that this is a relaxation lifetime of the luminescence centre. Based on this we can deduce that it is likely that there is only one dominant centre emitting UV luminescence in our samples. In summary, our samples have the typical quartz recombination center which gives rise to the measured emission for all the given doses, for both fine and coarse grain samples.

\section{Relation between stratigraphy and luminescence chronologies}

Marković et al. (2014) provided chronostratigraphic interpretation of the Orlovat section based on detailed litho- and pedo-stratigraphy, enviromagnetic parameters, as well as preliminary coarse grain quartz luminescence ages. The results show that the approximately $10 \mathrm{~m}$ thick section preserves an a typical Late Pleistocene succession for the Carpathian Basin (Fitzismmons et al., 2012). Notably, the normally widespread pedocomplex V-L1S1 is missing (e.g. Marković et al., 2008). This contrasts with other parts of the sequence which appear extremely highly resolved, such as the thicker pedocomplex V-S1 and the detailed transitions between interglacial pedocomplexes $\mathrm{V}-\mathrm{S} 1$ and $\mathrm{V}-\mathrm{S} 0$, with the last glacial loess unit V-L1 (Marković et al., 2014).

Figure 2 shows, similar to Romanian loess-paleosol sequences, that luminescence ages derived from coarser material (at least for equivalent doses higher than 100 Gy) seem to better fit the expected geological ages. Samples taken from the penultimate glacial loess layer V-L2 and pedocomplex V-S1 obtained on coarse quartz provide an almost perfect match to the expected geological age.

At this section, evidence for the middle pleniglacial pedogenesis is not observed in contrast to other sections in the Vojvodina region (Marković et al., 2008; Stevens et al., 2011). This anomaly in the Orlovat enviromagnetic record indicates a potential depositional hiatuses between approximately 2.5 and $2 \mathrm{~m}$ depth in the Orlovat profile. This is partly supported by the luminescence dates. After a relatively smooth decrease in luminescence ages from the top of paleosol V-S1 to the middle part of the last glacial loess unit V-L1 a chronological shift occurs below and above sample ORL 6 indicating a significant reduction in accumulation rates, or the 
likely occurrence of a hiatus in sedimentation (Marković et al., 2014). To identify more precisely these depositional gaps we plan to apply more detailed sampling for luminescence dating, similar to that presented in the recent studies of Stevens et al. $(2006 ; 2007 ; 2008)$ on the Chinese Loess Plateau. Thus, two independent lines of evidence, the magnetic record and luminescence chronology, confirm a discontinuity in deposition as suggested by an incomplete stratigraphy when compared to sections further west. However, on the basis of the existing results it is very difficult to precisely indicate the age of the hiatuses at Orlovat loess-palaeosol sequence, especially because of the large variability in the sedimentological and pedological characteristics of pedocomplex V-L1S1 in the region (Marković et al., 2014).

Luminescence dates obtained on both coarse and fine material clearly demonstrate an Early Holocene age almost $0.7 \mathrm{~m}$ below the Holocene soil V-S0. This raises important questions regarding the onset of soil formation and the cessation of loess deposition in the region (Marković et al., 2014).

From a methodological point of view, it is very important to note the agreement between the fine and coarse quartz ages obtained for the two uppermost samples. The observed agreement can be considered an indication that the discrepancy between the fine and the coarse grain ages is a dose dependent phenomenon.

There is a clear better agreement of the coarse grained ages with the expected ages for the penultimate glacial loess layer V-L2 and pedocomplex V-S1. The coarse grain ages seem to provide a solid chronology for V-L1 as well, while the fine quartz ages seem to slightly underestimate the expected ages in the lower part of this unit. This was also observed for Romanian loess, but intriguingly, the application of post $I R-\mathrm{IR}_{225}$ on polymineral fine grains on Mircea-Vodă section lead to obtaining feldspar ages that confirm the fine quartz chronology for L1, although in the case of L2 the agreement was observed between the post IR-IR 225 and coarse quartz ages (Vasiliniuc et al., 2012). Taking into consideration the above mentioned, as well as the fact that the cause of the observed discrepancy remains not understood none of the two chronologies can be discarded or favoured at the time being and further investigations are required.

\section{Conclusions}


313 Except for the two youngest samples, with equivalent doses of <100 Gy, the remaining eight 314 samples collected form L1, S1 and L2 units of Orlovat section (Vojvodina, Serbia) investigated in this work presented the same general OSL behaviour as quartz extracted from Romanian loess, meaning that the equivalent doses obtained on coarse quartz were systematically higher than the equivalent doses obtained using fine quartz. All samples passed adequately recycling, recuperation, IR depletion and dose recovery tests and the thermal stability of the investigated signals was confirmed through preheat plateau tests and pulse anneal experiments.

As in the case of quartz extracted from Romanian loess, the OSL growth curve as function of dose could be well fitted by a sum of two saturating exponential functions, and a marked difference between the saturation characteristics of fine and coarse grains was observed. This behaviour can be confidently attributed to quartz and not to feldspar contamination, as it was also observed in the case of pulsed-OSL stimulation where a deliberate rejection of any possible feldspar signal was achieved using signal gating. Photon- arrival-time distributions obtained in time resolved OSL investigations have been well fitted with one single exponential decay function, and the lifetimes obtained range in the typical interval for quartz (36.5-38.5 $\mu$ s) for natural as well as regenerated signals for doses as high as $1 \mathrm{kGy}$. The lack of dependency of luminescence lifetimes with dose strongly suggests that there is only one luminescence centre emitting in our detection window. Thus, the second saturating exponential component observed in the dose response pattern cannot be interpreted as the result of the presence of another UV emitting centre, although we cannot rule out competition with another center which is either nonradiative or emitting in a different detection window. Nonetheless, the results of the present study clearly indicate that the age discrepancy obtained on fine and coarse grains of loess is more widespread than previously thought; it is not restricted to just the Lower Danube basin but applies to loess form Vojvodina as well. In the absence of a clear understanding of the causal mechanism, we recommend caution with interpretation of the quartz SAR-OSL ages for samples that display a double exponential dose response curve, at least in the high dose range.

\section{Acknowledgements}

A.T-G. and D.C. acknowledge the financial support from a grant of the Romanian National Authority for Scientific Research CNCS-UEFISCDI, PN-II-RU-TE-2011-3-0062, nr. 73/05.10.2011. Also D.C. acknowledges the financial support of the Sectorial Operational 
Programme for Human Resources Development 2007-2013, co-financed by the European Social Fund, under the project POSDRU/159/1.5/S/133391-"Doctoral and postdoctoral excellence programs for training highly qualified human resources for research in the fields of Life Sciences, Environment and Earth".

\section{References}

1. Adamiec, G.,Aitken, M.J., 1998. Dose-rate conversion factors: update. Ancient TL 16(2), $37-50$.

2. Aitken, M.J., Alldred, J.C., 1972. The assessment of error limits in thermoluminescent dating. Archaeometry 14, 257-267.

3. Aitken, M. J., 1976. Thermoluminescent age evaluation and assessment of error limits: revised system. Archaeometry 18, 233-238.

4. Aitken, M. J., 1985. Thermoluminescence dating. Academic press, 359p, ISBN: 0-12046380-6.

5. Ankjærgaard, C., Jain, M., Thomsen K.J., Murray A.S., 2010. Optimising the separation of quartz and feldspar optically stimulated luminescence using pulsed excitation. Radiation Measurements 45, 778-785.

6. Buggle, B., Glaser, B., Zöller, L., Hambach, U., Markovic, S., Glaser, I., Gerasimenko, N., 2008. Geochemical characterisation and origin of Southeastern and Eastern European loesses (Serbia, Romania, Ukraine). Quaternary Science Reviews 27, 1058-1075.

7. Buylaert, J.P., Vandenberghe, D., Murray, A.S., Huot, S., De Corte, F. and Van den Haute, P., 2007. Luminescence dating of old (>70ka) Chinese loess: a comparison of single aliquot OSL and IRSL techniques. Quaternary Geochronology 2, 9-14.

8. Chithambo, M. L., 2003. Dependence of the thermal influence on luminescence lifetimes from quartz on the duration of optical stimulation. Radiation Measurements 37, 167-175.

9. Chithambo, M.L., Ogundare, F.O., Feathers, J., Hong, D. G., 2008. The dependence of luminescence lifetimes on additive irradiation on natural sedimentary quartz: sands from Santa Elina, Brazil. Physica Status Solidi (c) 2, 630-633.

10. Choi, J.H., Murray, A.S., Cheong, C.S., Hong, D.G., Chang, H.W., 2003. The resolution of stratigraphic inconsistency in the luminescence ages of marine terrace sediments from Korea. Quaternary Science Reviews 22, 1201-1206. 
11. Constantin, D., Timar-Gabor, A., Veres, D., Begy, R., Cosma, C., 2012. SAR-OSL dating of quartz of different grain sizes extracted from a loess section in southern Romania embedding the Campanian Ignimbrite/Y5 tephra layer, Quaternary Geochronology 10, 81-86.

12. Constantin, D., Begy, R., Vasiliniuc, S., Panaiotu, C., Necula, C., Codrea, V., TimarGabor, A., 2014. High resolution OSL dating of the Costinești section Romania using fine and coarse quartz. Quaternary International 234-235, 20-29.

13. Constantin, D., Camenita, A., Panaiotu, C., Necula, C., Codrea, V., Timar-Gabor, A., 2014 online published. Fine and coarse-quartz SAR-OSL dating of Last Glacial loess in Southern Romania. Quaternary International, doi:10.1016/j.quaint.2014.07.052.

14. Cunningham, A.C., Wallinga, J., 2010. Selection of integration time intervals for quartz OSL decay curves. Quaternary Geochronology 5, 657-666.

15. Denby, P.M., Bøtter-Jensen, L., Murray, A.S., 2006, Thomsen K.J., Moska P., 2006. Application of pulsed OSL to the separation of the luminescence components from a mixed quartz/feldspar sample. Radiation Measurements 41, 774-779.

16. Duller, G.A.T., 2003. Distinguishing quartz and feldspar in single grain luminescence measurements. Radiation Measurements 37, 161-165.

17. Fan, A., Li, S-H., Li B., 2011. Observation of unstable fast component in OSL of quartz. Radiation Measurements 46, 21-28.

18. Fitzsimmons, K., Marković, S.B., Hambach, U. 2012. Pleistocene environmental dynamics recorded in the loess of the middle and lower Danube basin. Quaternary Science Reviews 41, 104-118.

19. Kreutzer, S., Fuchs, M., Meszner, S., Faust, D., 2012. OSL chronostratigraphy of a loesspalaeosol sequence in Saxony/Germany using quartz of different grain sizes. Quaternary Geochronology 10, 102-109.

20. Lapp, T., Jain, M., Ankjærgaard, C., Pirtzel, L., 2009. Development of pulsed stimulation and Photon Timer attachements to the Risø TL/OSL reader. Radiation Measurements 44, 571-575.

21. Li, B., Li, S.-H., 2006. Comparison of De estimates using the fast component and the medium component of quartz OSL. Radiation. Measurements 41, 125-136. 
22. Lowick, S.E., Preusser, F., Pini, R., Ravazzi, C., 2010a. Underestimation of fine grain quartz OSL dating towards the Eemian: comparison with palynostratigraphy from AzzanoDecimo, northeastern Italy. Quaternary Geochronology 5, 583-590.

23. Lowick, S.E., Preusser, F., Wintle, A.G., 2010b. Investigating quartz optically stimulated luminescence dose-response curves at high doses. Radiation Measurements 45, 975-984.

24. Lowick, S.E., Preusser, F., 2011. Investigating age underestimation in the high dose region of optically stimulated luminescence using fine grain quartz. Quaternary Geochronology 6, 33-41.

25. Lukić, T., Basarin, B., Buggle, B., Marković, S.B., Tomović, V.M., Popov-Raljić,J., Hrnjak, I., Timar-Gabor, A., Hambach, U., Gavrilov, M.B., 2014. A joined rock magnetic and colorimetric perspective on the Late Pleistocene climate of Orlovat loess site (Northern Serbia). Quaternary International 234-235, 179-188.

26. Marković, S.B., Bokhorst, M.P., Vandenberghe, J., McCoy, W.D., Oches, E,A,, Hambach, U., Gaudenyi, T., Jovanović, M., Zöller, L., Stevens, T., Machalett, B. 2008. Late Pleistocene loess-paleosol sequences in the Vojvodina region, north Serbia. Journal of Quaternary Science 23, 73-84.

27. Marković, S.B., Hambach, U, Jovanović, M., Stevens, T., O’Hara-Dhand, K., Basarin, B., Smalley. I.J., Buggle, B., Zech, M., Svirčev, Z., Milojković, N., Zöller, L. 2012. Loess in Vojvodina region (Northern Serbia): the missing link between European and Asian Pleistocene environments. Netherlands Journal of Geosciences 91, 173-188.

28. Marković, SB., Timar-Gabor, A., Stevens, T., Hambach, U., Popov, D., Tomić, N., Obreht I., Janović M., Lemhkuhl, F., Kels, H., Marković, R., Gavrilov M.B., 2014. Environmental dynamics and luminescence chronology from Orlovat loess-palaeosol sequence (Vojvodina, Northern Serbia). Journal of Quaternary Science 29 (2), 189-199

29. Martinson, D.G., Pisias, N.G., Hays, J.D., Imbrie J.L., Moore, Jr. T.C., Shackleton, N.J. 1987. Age dating and the orbital theory of the ice ages: development of a high resolution 0 to 300,000-year chronostratigraphy. Quaternary Research 27, 1-29.

30. Murray, A.S., Wintle, A.G., 2000. Luminescence dating of quartz using an improved single-aliquot regenerative-dose protocol. Radiation Measurements 32, 57-73.

31. Murray, A.S., Wintle, A.G., 2003. The single aliquot regenerative dose protocol: potential for improvements in reliability. Radiation Measurements 37, 377-381. 
32. Murray, A.S., Svendsen, J.I., Mangerud, J., Astakhov, V.I., 2007. Quartz OSL age of an Eemian site on the Sula River, Northern Russia. Quaternary Geochronology 2, 107-109.

33. Pagonis, V., Ankjærgaard C., Murray, A.S., Jain, M., Chen R., Lawless, J., Greilich S., 2010. Modelling the thermal quenching mechanism in quartz based ontime-resolved optically stimulated luminescence. Journal of Luminescence 130, 902-909.

34. Pagonis, V., Lawless, J., Chen, R., Chithambo, M.L., 2011. Analytical expressions for time-resolved optically stimulated luminescence experiments in quartz. Journal of Luminescence 131, 1827-1835.

35. Pawley, S.M., Toms, P., Armitage, S.J., Rose, J., 2010. Quartz luminescence dating of Anglian Stage (MIS 12) fluvial sediments: Comparison of SAR age estimates to the terrace chronology of the Middle Thames valley, UK. Quaternary Geochronology 5, 569582.

36. Prescott, J.R., Hutton, J.T., 1994. Cosmic ray contributions to dose rates for luminescence and ESR dating: Large depths and long term variations. Radiation Measurements 23(2-3), 497-500.

37. Steffen, D., Preusser, F., Schlunegger, F., 2009. OSL quartz age underestimation due to unstable signal components. Quaternary Geochronology 4, 353-362.

38. Stevens, T., Armitrage, S.J., Lu, H., Thomas, D.S.G., 2006. Sedimentation and diagenesis of Chinese loess: implications for the preservation of continuous, high-resolution climate records. Geology 34, 849-852.

39. Stevens, T,, Thomas, D.S.G., Armitage, S.J., Lunn, H.R., Lu, H,. 2007. Reinterpreting climate proxy records from the late Quaternary Chinese loess: A detailed OSL investigation. Earth Science Reviews 80, 111-136.

40. Stevens, T, Lu, H., Thomas, D.S.G., Armitage, S.J. 2008. Optical dating of abrupt shiftd in the late Pleistocene East Asian monsoon. Geology 36, 415-418.

41. Stevens, T., Marković, S.B., Zech, M., Hambach, U., Sümegi, P. 2011. Dust deposition and climate in the Carpathian Basin over an independently dated last glacial-interglacial cycle. Quaternary Science Reviews 30, 662-681.

42. Thomsen, K.J., Bøtter-Jensen, L., Denby, P.M.,Moska P., Murray, A.S., 2006. Developments in luminescence measurement techniques. Radiation Measurements 41, 768-773. 
43. Thomsen, K.J., Jain, M., Murray A.S., Denby, P.M., Roy, N, Bøtter-Jensen, L., 2008. Minimising feldspar OSL contamination in quartz UV-OSL using pulsed blue stimulation. Radiation Measurements 43, 752-757.

44. Timar, A., Vandenberghe, D., Panaiotu, E.C., Panaiotu, C.G., Necula, C., Cosma, C., Van den haute, P., 2010. Optical dating of Romanian loess using fine-grained quartz. Quaternary Geochronology 5, 143-148.

45. Timar-Gabor, A., Vandenberghe, D.A., Vasiliniuc, S., Panaiotu, C.E., Panaiotu, C.G., Dimofte, D., Cosma, C., 2011. Optical dating of Romanian loess: a comparison between sand-sized and silt-sized quartz. Quaternary International 240, 62-70.

46. Timar-Gabor, A.,Vasiliniuc, Ş., Vandenberghe, D.A.G., Cosma, C, Wintle, A.G., 2012. Investigations on the reliability of SAR-OSL equivalent doses obtained for quartz samples displaying dose response curves with more than one component. Radiation Measurements 47, 740-745.

47. Timar-Gabor, A., Wintle, A.G., 2013. On natural and laboratory generated dose response curves for quartz of different grain sizes from Romanian loess. Quaternary Geochronology 18, 34-40.

48. Vandenberghe, D., De Corte, F., Buylaert, J-P., Kučera, J., Van den haute, P., 2008. On the internal radioactivity in quartz. Radiation Measurements 43, 771-775.

49. Vasiliniuc Ş., Vandenberghe, D.A.G., Timar-Gabor A., Panaiotu C., Cosma C. ,Van den haute P., 2012. Testing the potential of elevated temperature post-IR-IRSL signals for dating Romanian loess, Quaternary Geochronology, 10, 75-80.

50. Wintle, A.G., 2008. Luminescence dating: where it has been and where it is going. Boreas 37, 471-482.

\section{(1)} 3 
Table 1. Equivalent dose estimation results. The uncertainties mentioned with luminescence and radionuclide specific activity data are random errors. Data marked by * represent the results obtained applying a thermal treatment consisting of ph $10 \mathrm{~s}$ at $260{ }^{\circ} \mathrm{C}$ and cutheat to $180{ }^{\circ} \mathrm{C}$. These additional experiments have been performed in order to increase the confidence in the robustness of the equivalent doses obtained and to further emphasize that these values are not affected by the thermal treatment applied. The IR stimulation treatment implied in the IR depletion ratio tests (Duller, 2003) consisted of $40 \mathrm{~s}$ stimulation at a temperature of $60^{\circ} \mathrm{C}$. Table 2. Summary of the luminescence age results. The uncertainties coming along with the luminescence and the dosimetry data (including annual dose rates) are random; the uncertainties indicated with the optical ages are the overall uncertainties. All associated uncertainties represent $1 \sigma$. The associated uncertainties were calculated based on the error assessment system reported by Aitken and Alldred (1972) and Aitken (1976). The quoted water content was determined based on the difference between the natural "as found" and the dry weight of the material extracted from the ends of the tubes, with a relative error of $25 \%$. The total dose rate comprises the contribution from the alpha, beta and gamma radiations as well as the contribution of the cosmic rays; in the case of the coarse fraction a factor of $0.01 \mathrm{~Gy} / \mathrm{ka}$ was adopted to account for the internal contribution (Vandenberghe et al., 2008). Cosmic ray contribution to the total dose rate was derived based on the equations published by Prescott and Hutton (1994). The dose rates were calculated using the conversion factors tabulated by Adamiec and Aitken (1998). For fine grains the alpha efficiency factor considered was $0.04 \pm 0.02$. A beta attenuation and etching 


\section{Figure captions}

Figure 1. Study area. Map of Vojvodina (Northern Sebia) (a) with the Tamiš loess plateau indicated and enlarged (b) (Marković et al., 2014, modified).

Figure 2. Stratigraphic column, description, sediment colour and magnetic properties of the investigated section compared with MIS (Martinson et al, 1987) and luminescence age results. The location of the samples investigated by luminescence is indicated by arrows (Marković et al., 2014, modified).

Figure 3. Dose recovery results for fine $(4-11 \mu \mathrm{m})$ grains (panel a) and coarse $(63-90 \mu \mathrm{m})$ grains (panel b) (Marković et al. 2014). Natural aliquots were bleached twice for $100 \mathrm{~s}$ at room temperature using the blue light emitting diodes; the two bleaching treatments were separated by a $10 \mathrm{ks}$ pause. The aliquots were then given a known dose chosen to be equal to the estimated equivalent dose, and measured using the SAR protocol. The solid line (eye guide) represents the 1:1 relation; the dotted lines (eye guide) bracket a 10\% deviation from unity.

Figure 4. (a) Results of the equivalent dose preheat plateau test. (b) Results of the high resolution pulse anneal test for natural and regenerated signal. For natural signals each data point presents the average value obtained on three aliquots of the ratio between the natural signal measured after different preheat (10 s) temperatures and a 16 Gy test dose signal. In the case of regenerated signals three fresh aliquots have been bleached, given a dose approximately equal to the equivalent dose, the OSL signal being measured at $125^{\circ} \mathrm{C}$ following different preheat (10 s) temperatures, each value being normalized to the response to a constant test dose of 16 Gy (cutheat to $180^{\circ}$ ). The insert presents data obtained using Ris $\varnothing$ calibration quartz.

Figure 5. Comparison of average SAR-OSL growth curves for fours samples of different ages using fine $(4-11 \mu \mathrm{m})$ grains and coarse $(63-90 \mu \mathrm{m})$ grains. The number of aliquots $(\mathrm{n})$ used to obtain the average is specified in the legend. The average dose response fitting function for all investigated aliquots of a certain grain size is also given.

Figure 6. Photon arrival time distribution recorded during on and off time. The sample was preheated to $220{ }^{\circ} \mathrm{C}$ and stimulated at $125^{\circ} \mathrm{C}$.

Figure 7. (a) Time resolved OSL curves (off time shown) of natural and regenerated signals of a representative aliquot of sample ORL 4 fine $(4-11 \mu \mathrm{m})$ grains produced for an on time of $50 \mu \mathrm{s}$ and an off time of $450 \mu \mathrm{s}$, by adding up signals recorded in 100s. Panel (b) presents the same 
559 data enlarged for the first $50 \mu$ s of the off time. The solid lines represent the best fit (single 560 exponential decay plus a constant (background)) of the data. Please note the logarithmic y-axis.

561 Figure 8. (a) Dose response curves for fine $(4-11 \mu \mathrm{m})$ grains and coarse $(63-90 \mu \mathrm{m})$ grains of 562 sample ORL 4 constructed using pulsed OSL data. Each data point represents the average value 563 obtained on four aliquots. The aliquots have been measured using a typical SAR protocol 564 measurement sequence. The test dose was $19 \mathrm{~Gy}$. The photomultiplier was gated to record only 565 during off time. Data was registered in 500 channels of 0.2 seconds, each channel consisting of 566400 pulses of stimulation. Data collected from second 1 to second 4 of signal registration was 567 selected for integration, which corresponds to a stimulation time interval of 0.32 seconds, a value 568 very similar to that used in CW-OSL (0.308s). (b) Average lifetimes obtained as function of 569 dose. The lifetimes of natural signals are depicted as stars. The IR stimulation was performed in 570 a pseudo-CW stimulation manner (on time $500 \mu \mathrm{s}$; off time $4.5 \mu \mathrm{s}$ ) for $100 \mathrm{~s}$ at $125{ }^{\circ} \mathrm{C}$.

571

572

573 


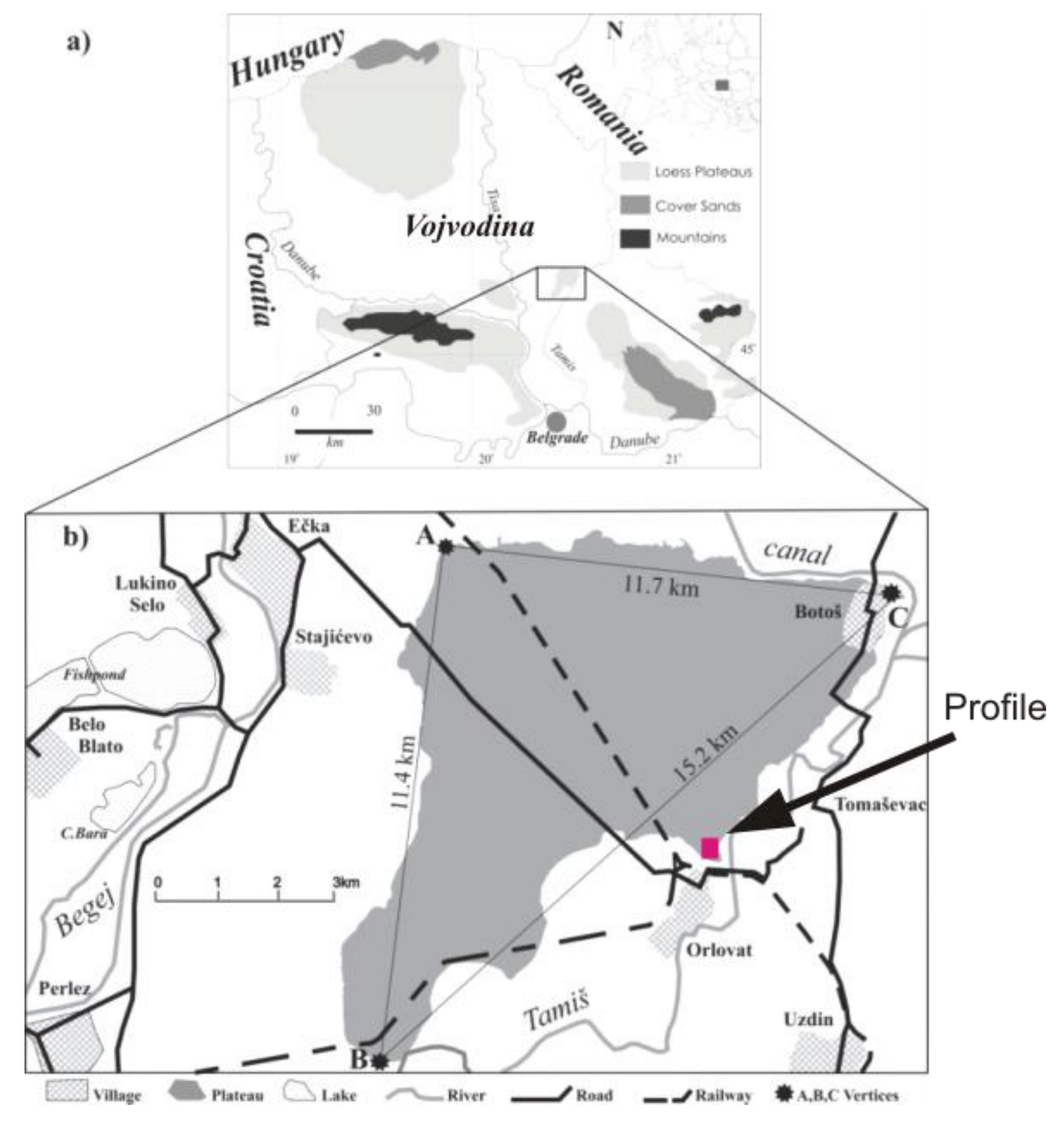




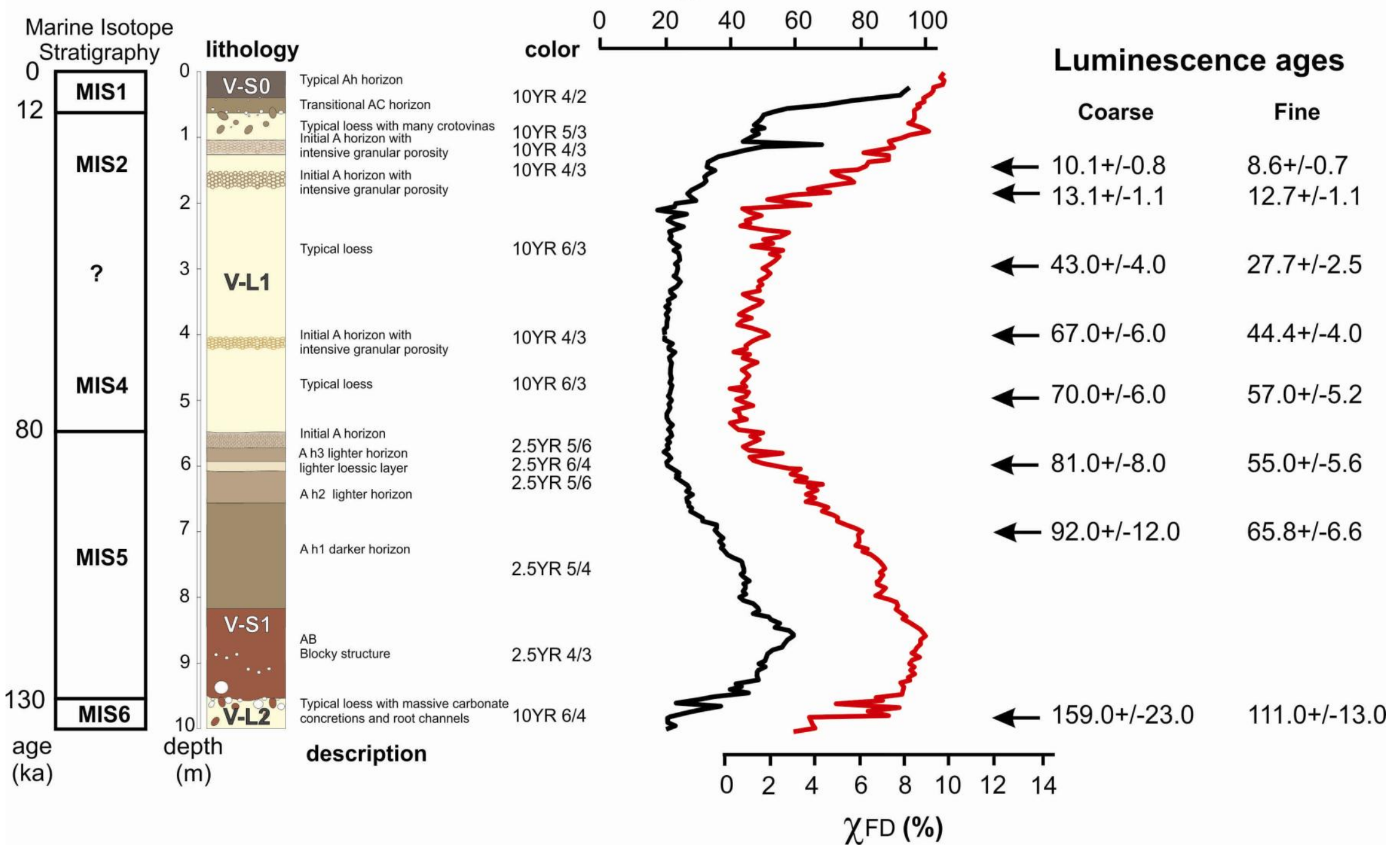




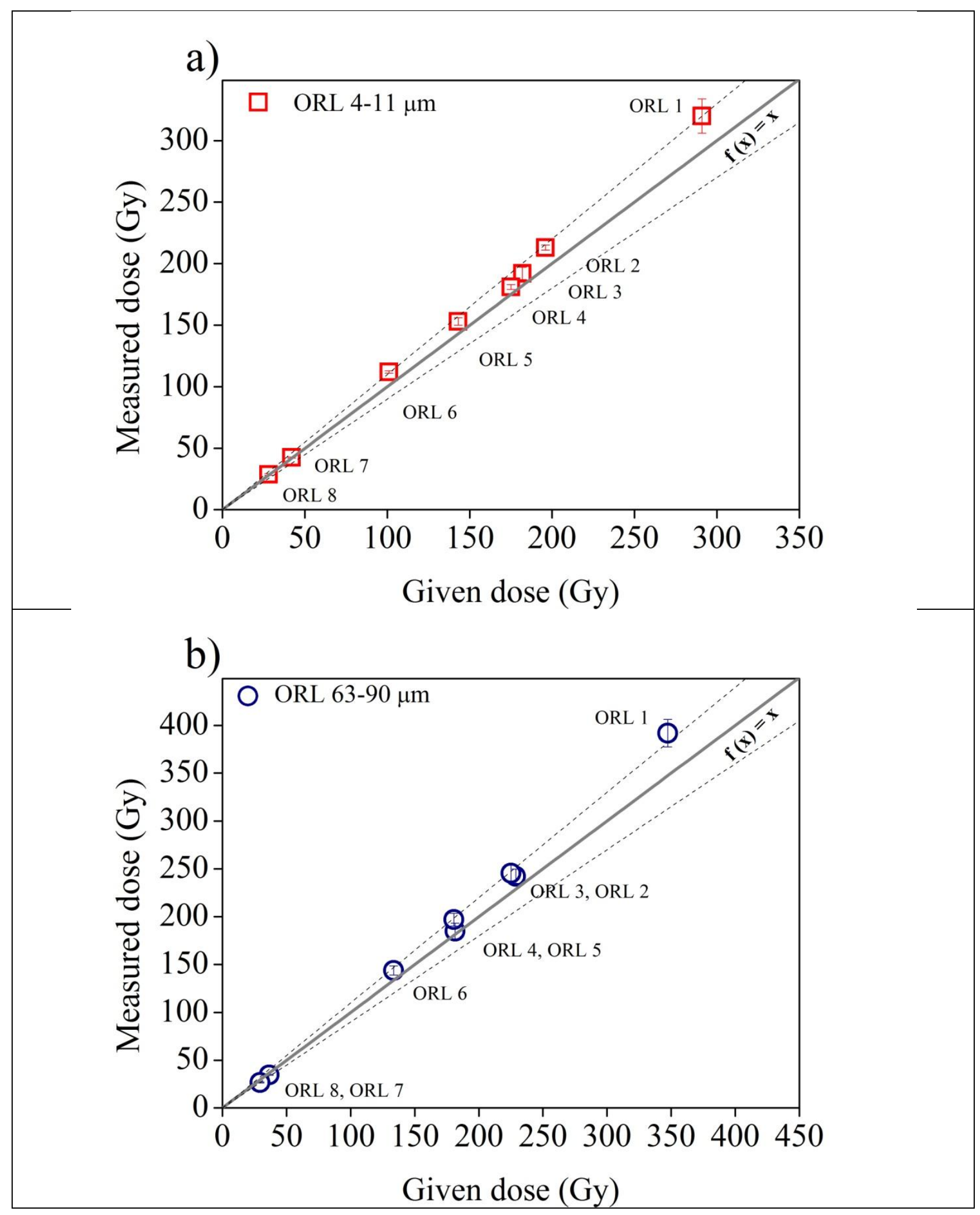




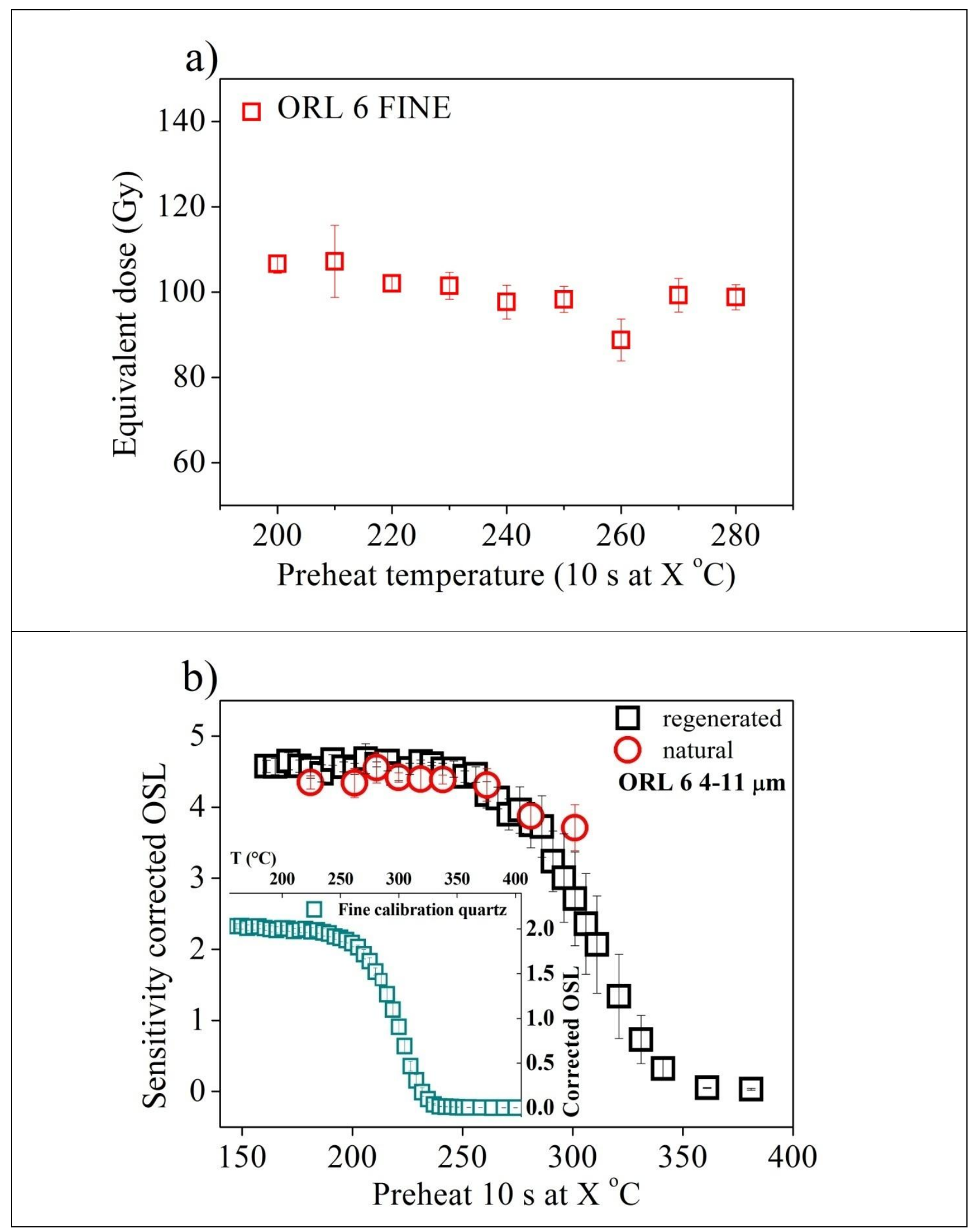




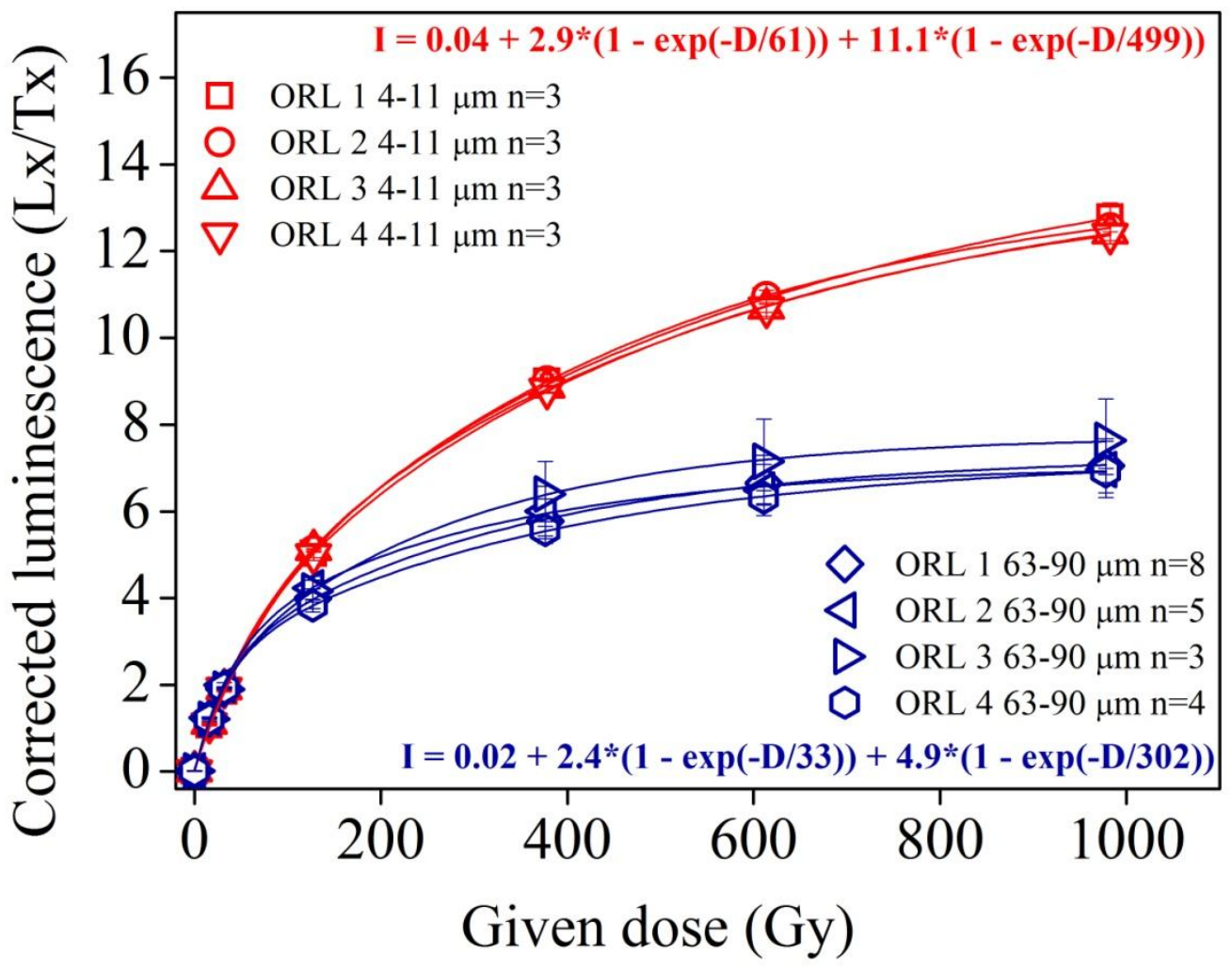




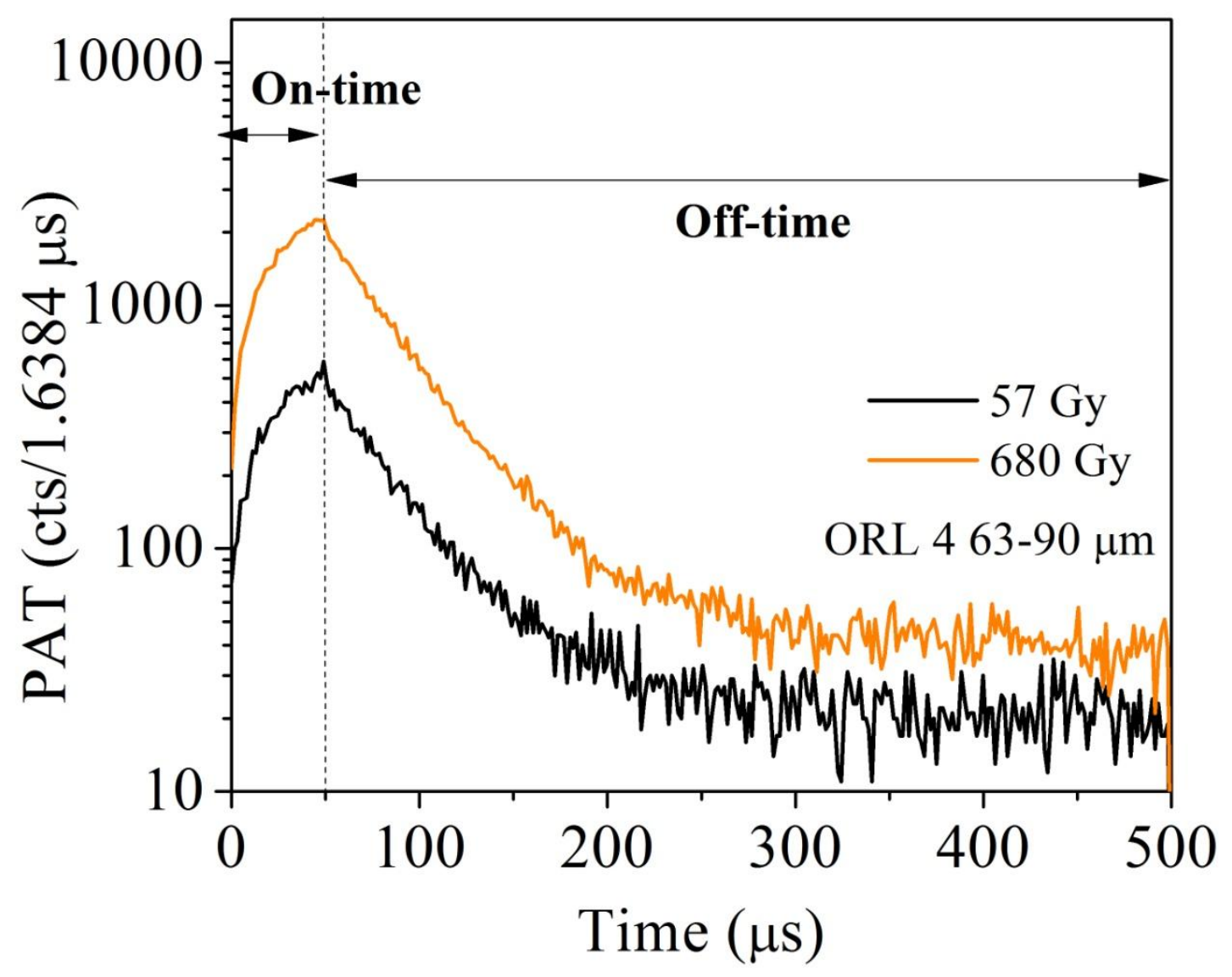




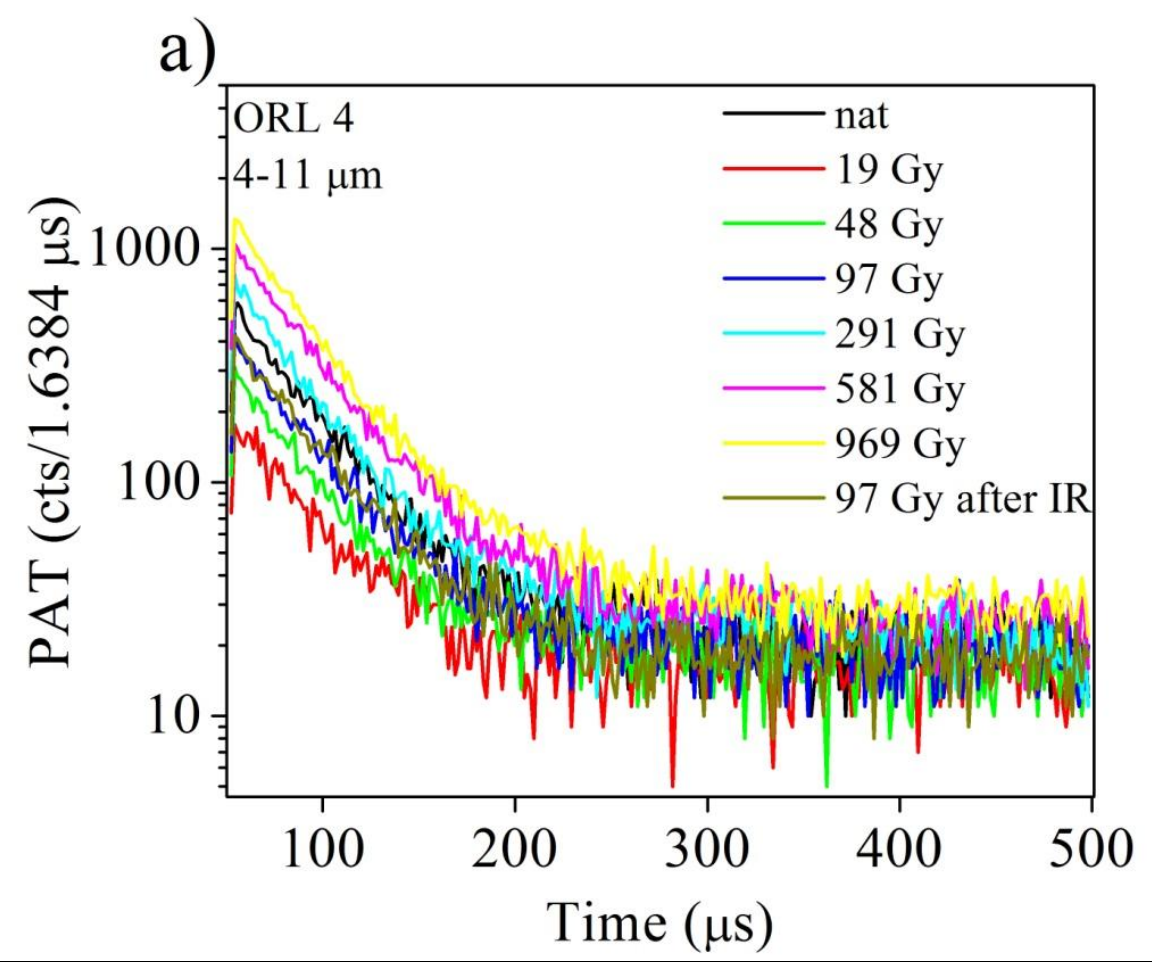

b)

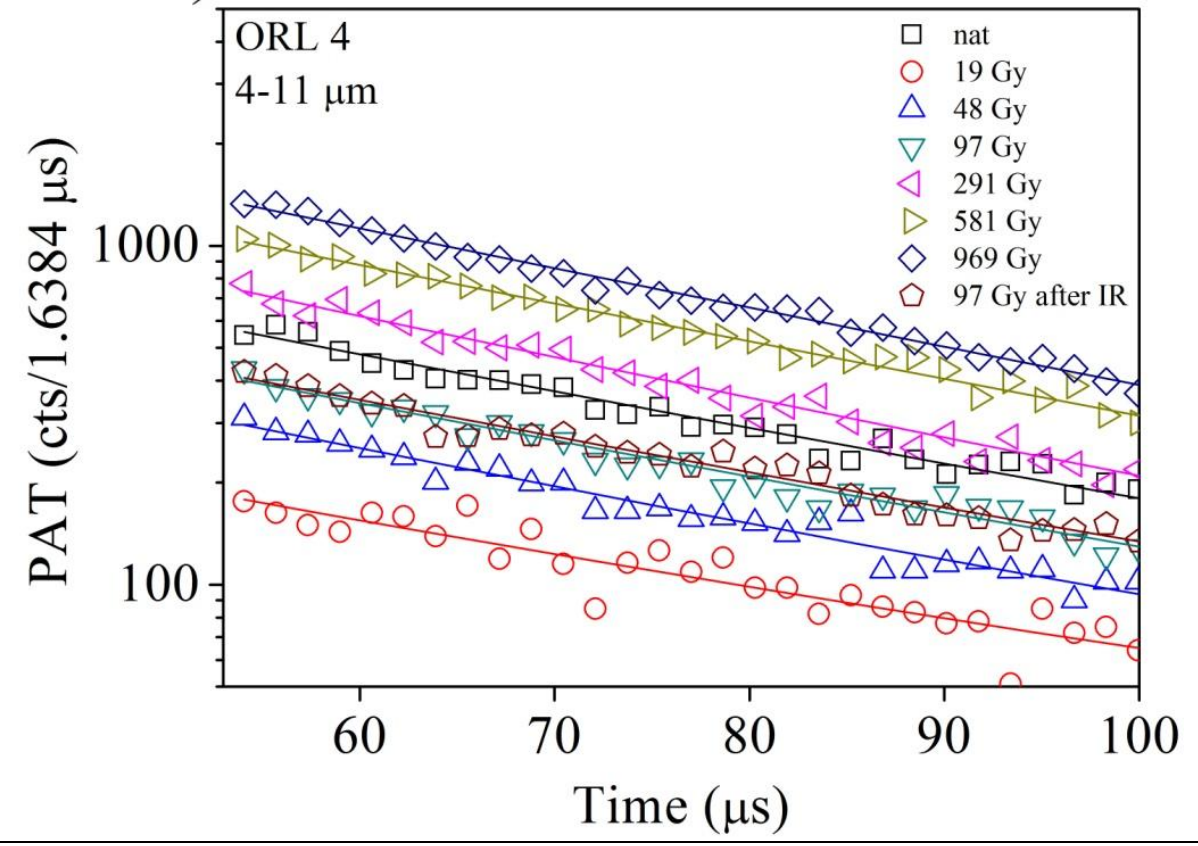


a)

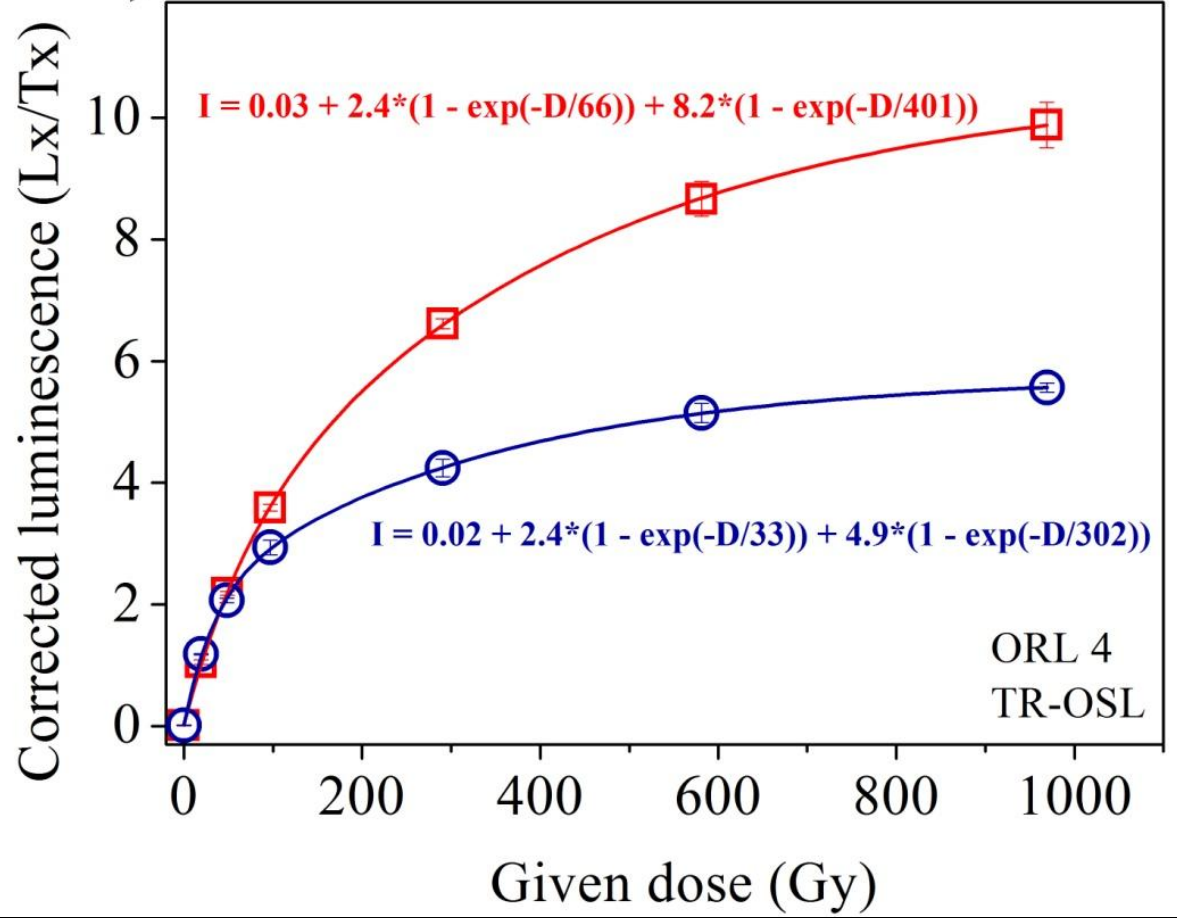

b)

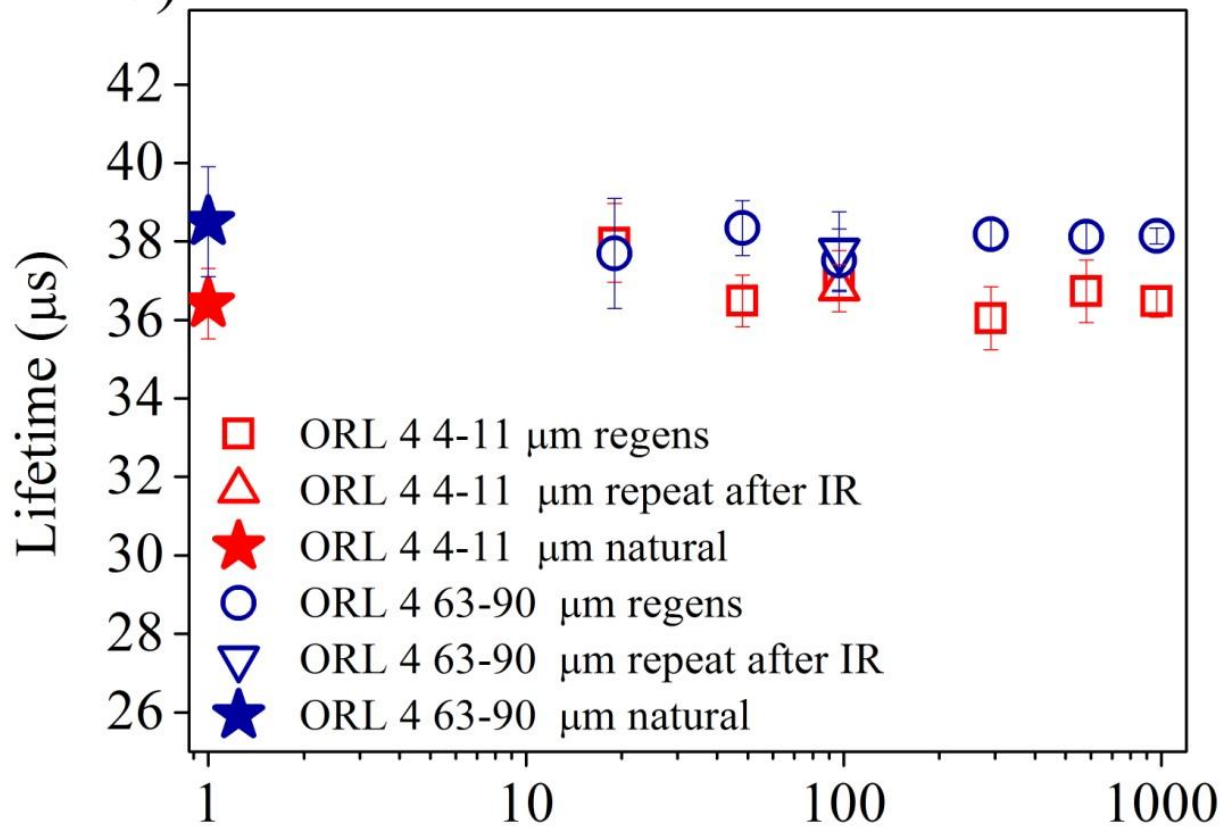

Given dose (Gy) 


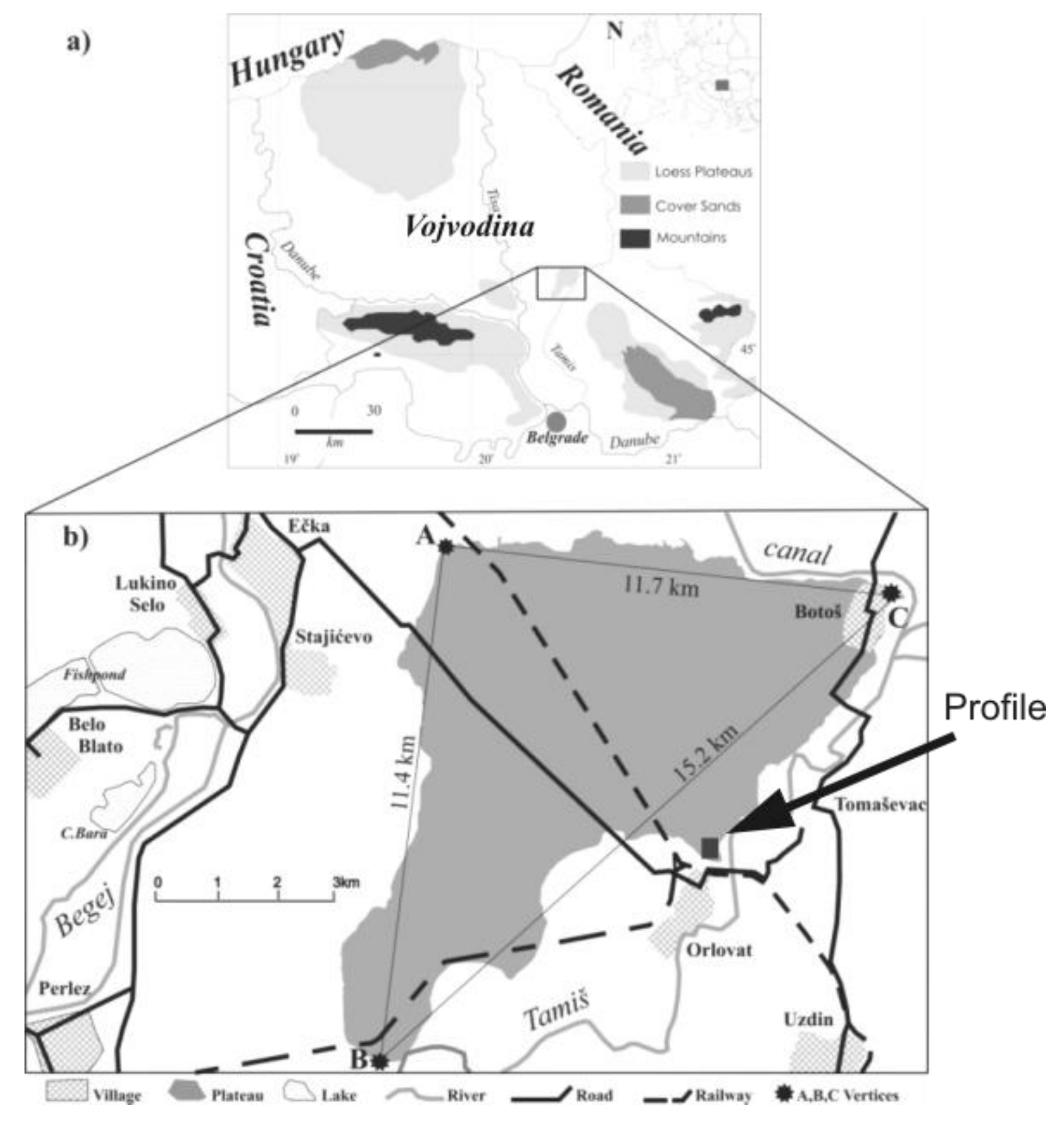




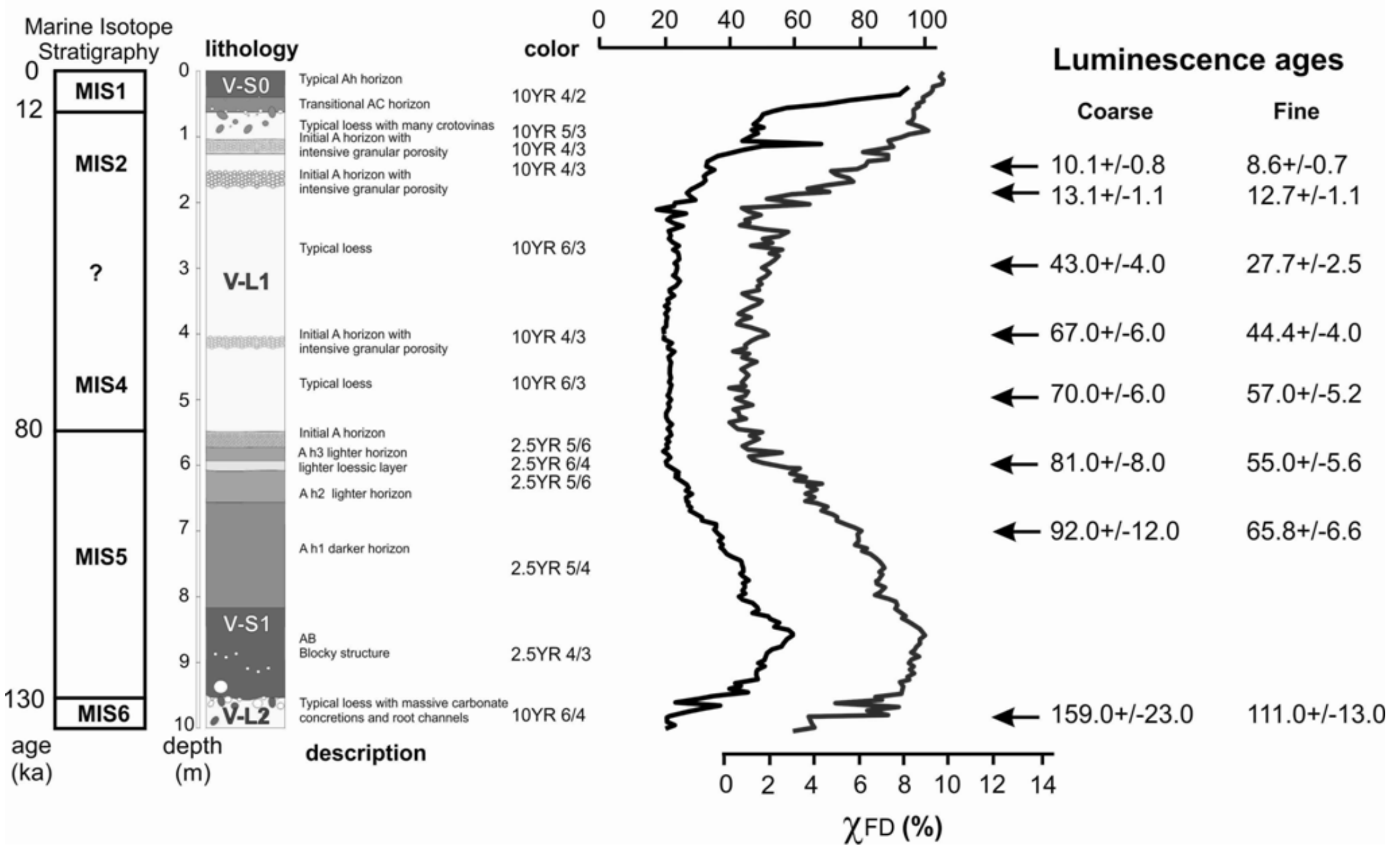




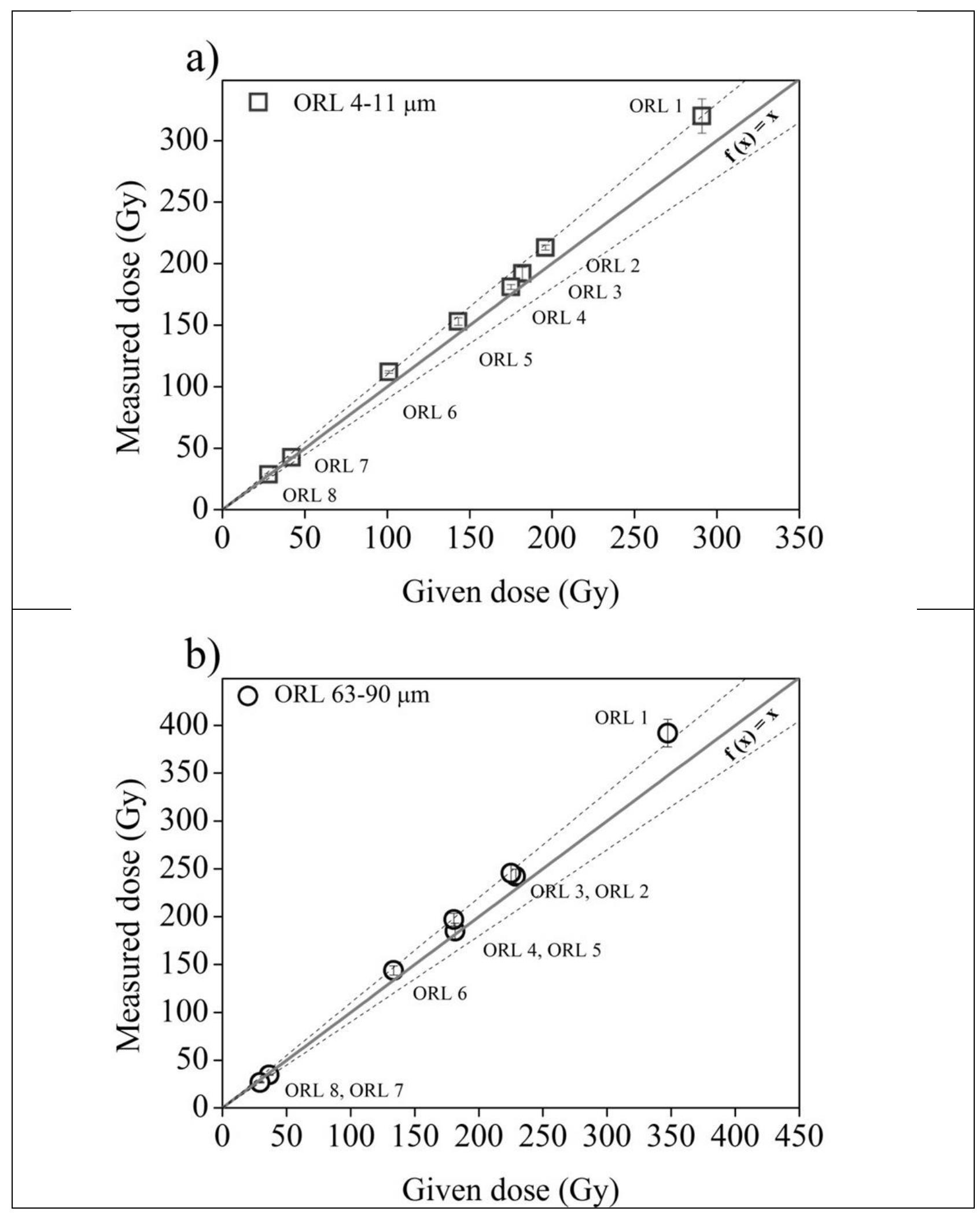




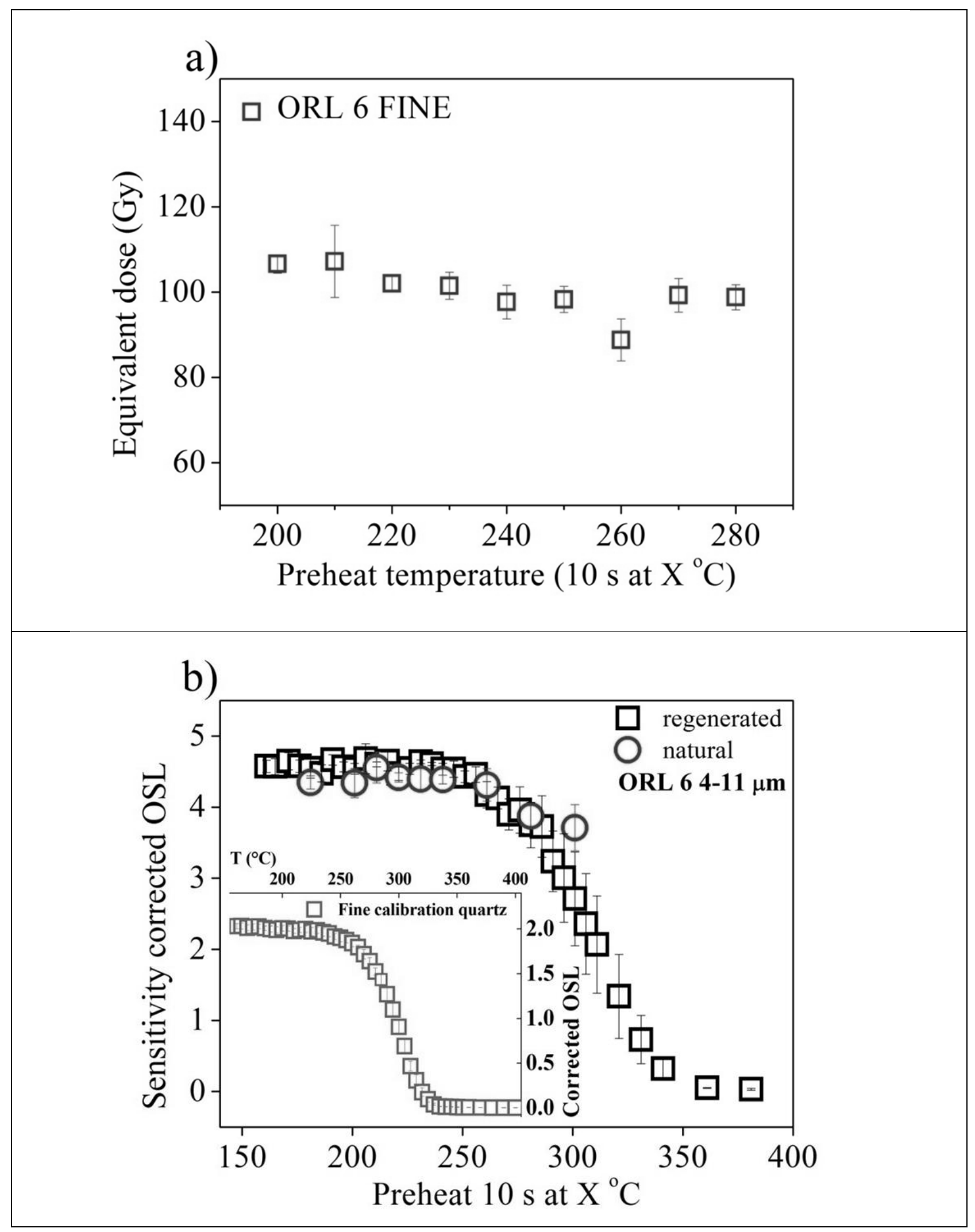




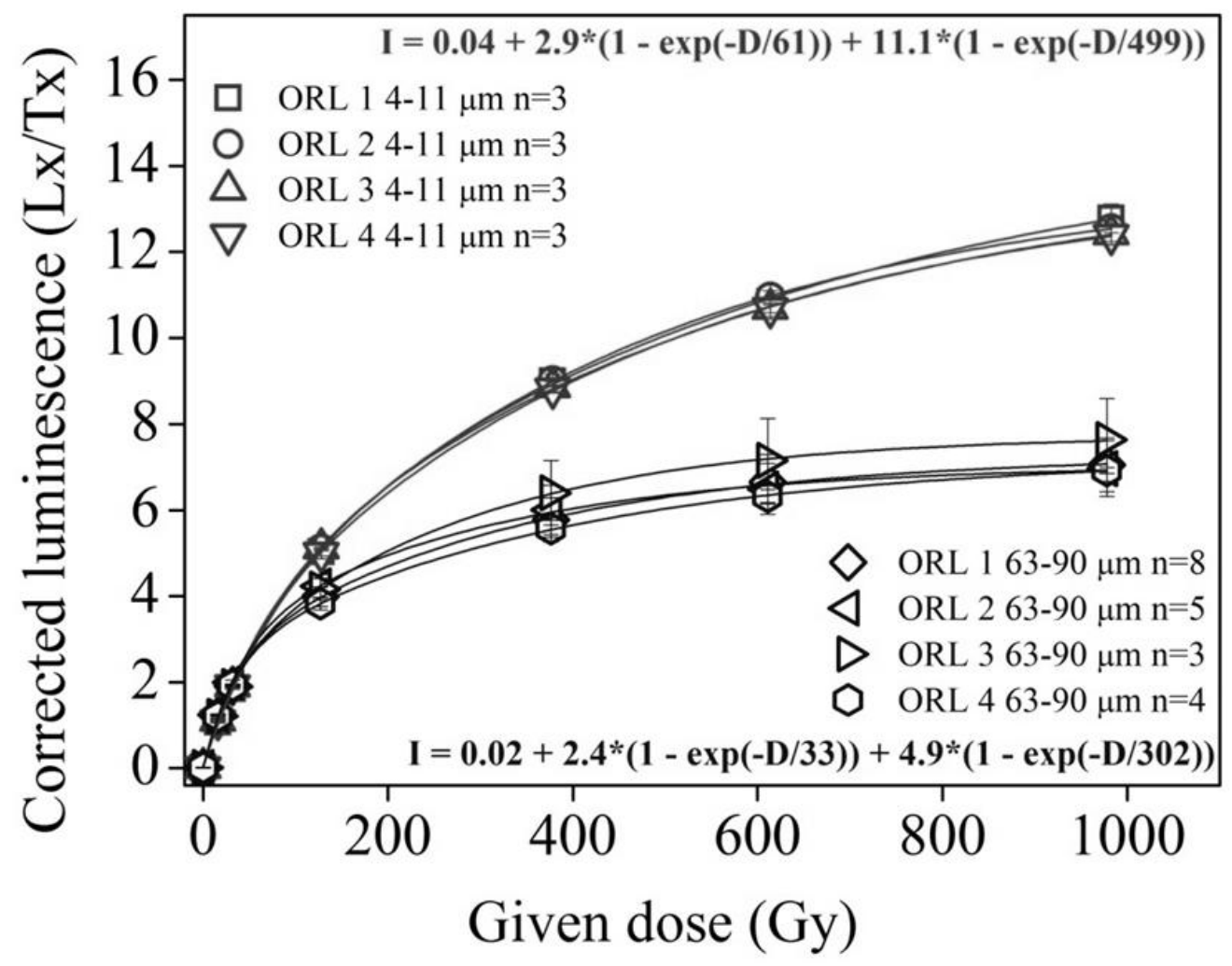




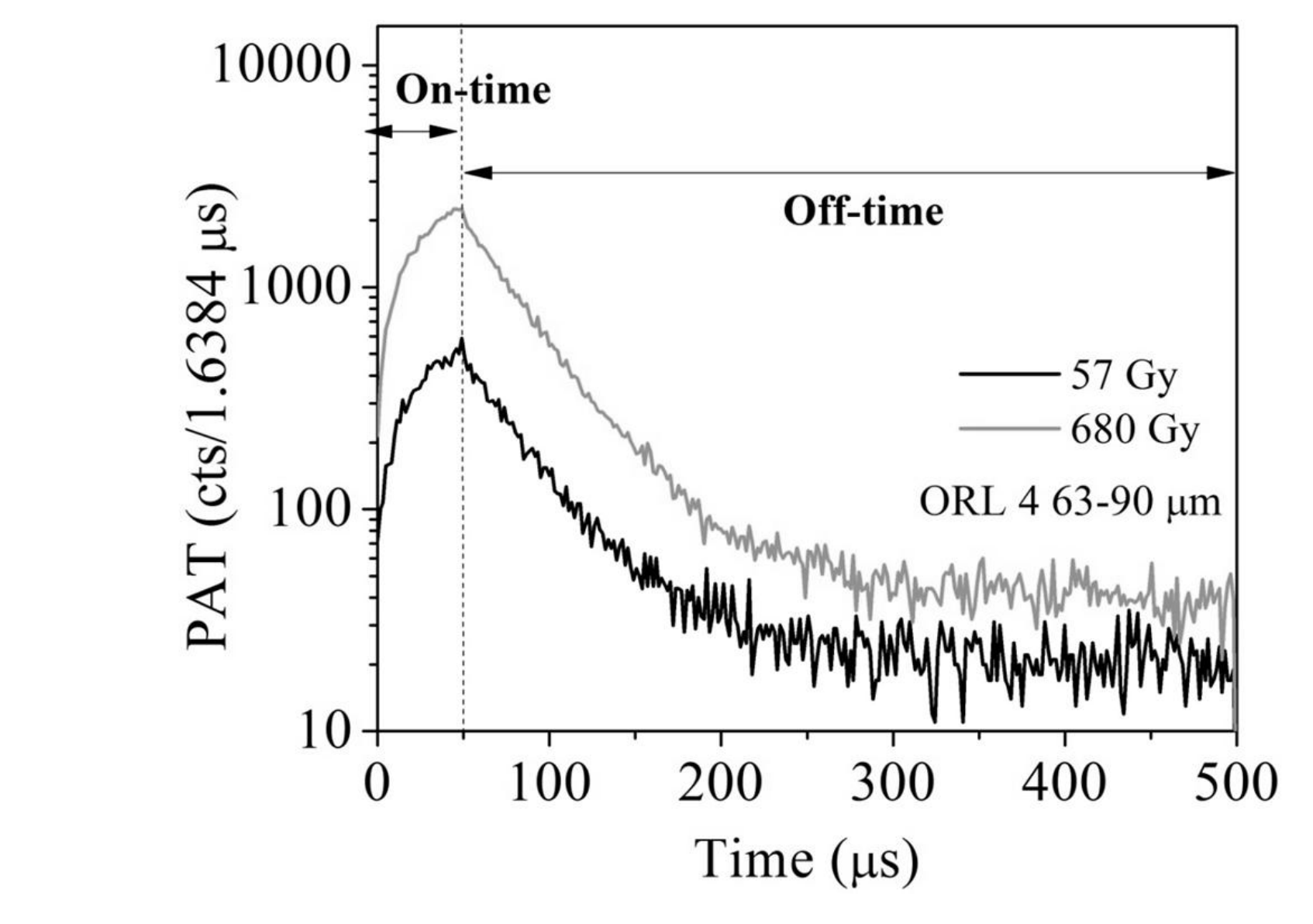

Figure 


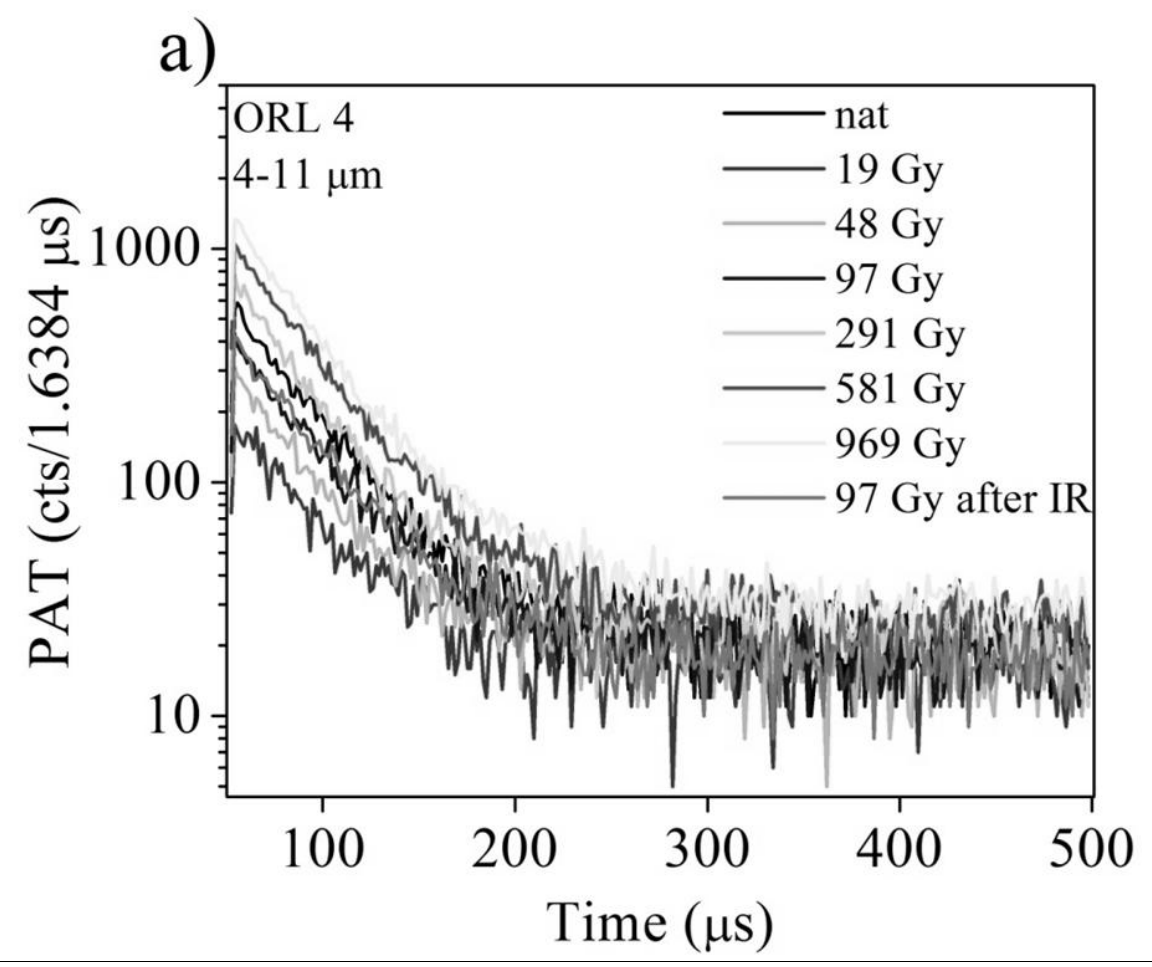

b)

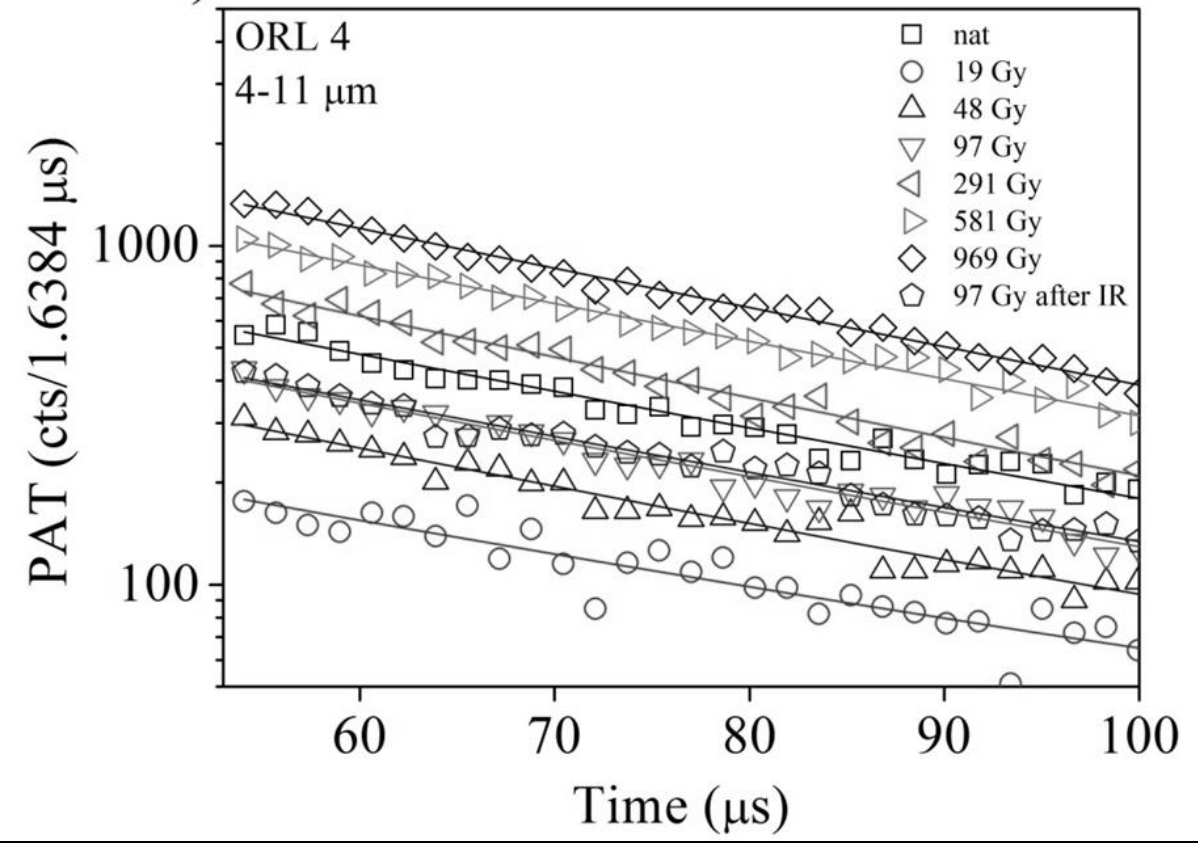


a)

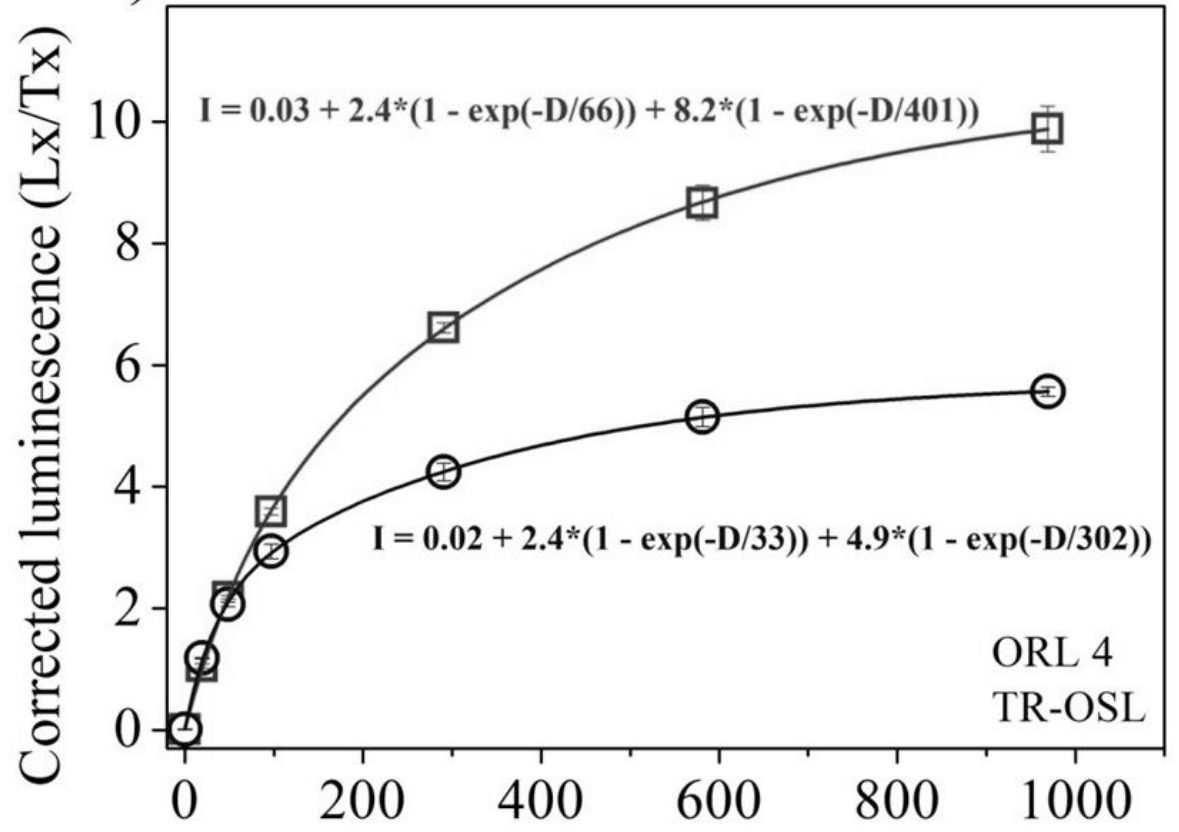

Given dose (Gy)

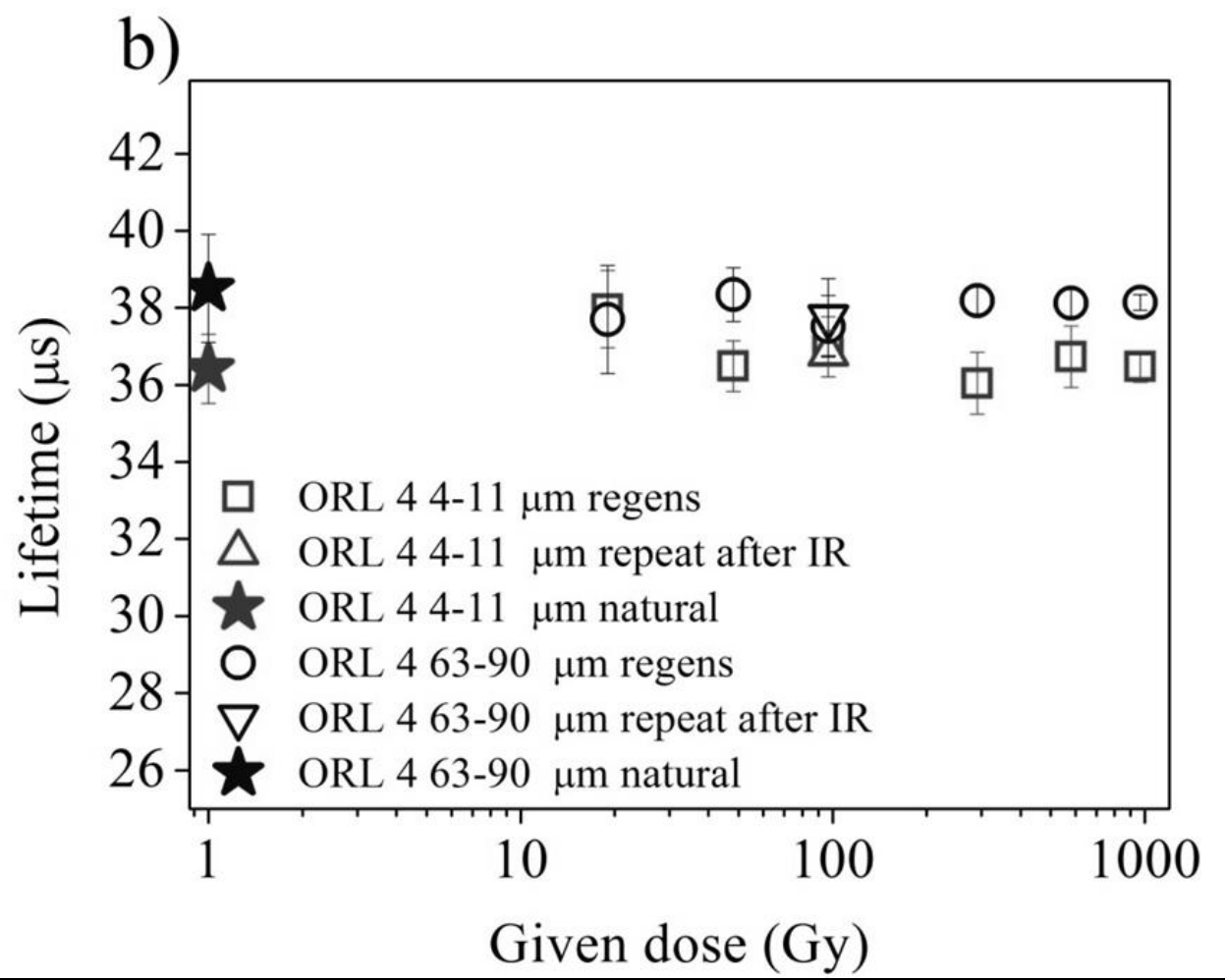




\begin{tabular}{ccccccc}
\hline SAMPLE & $\begin{array}{c}\text { Grain } \\
\text { size }\end{array}$ & $\begin{array}{c}\text { Number } \\
\text { of aliq }\end{array}$ & $\begin{array}{c}\text { Equivalent } \\
\text { Dose } \\
\text { (Gy) }\end{array}$ & $\begin{array}{c}\text { Recycling } \\
\text { ratio }\end{array}$ & $\begin{array}{c}\text { IR } \\
\text { depleation } \\
\text { ratio }\end{array}$ & $\begin{array}{c}\text { Recuperation } \\
\text { (\%) }\end{array}$ \\
\hline ORL 1 & $4-11 \mu \mathrm{m}$ & $8 / 9$ & $292 \pm 10$ & $0.96 \pm 0.01$ & $0.96 \pm 0.01$ & $0.09 \pm 0.01$ \\
& $63-90 \mu \mathrm{m}$ & $8 / 12$ & $347 \pm 38$ & $0.91 \pm 0.01$ & $0.93 \pm 0.01$ & $0.19 \pm 0.03$ \\
ORL 2 & $4-11 \mu \mathrm{m}$ & $9 / 9$ & $196 \pm 4$ & $0.95 \pm 0.01$ & $0.96 \pm 0.01$ & $0.10 \pm 0.01$ \\
& $63-90 \mu \mathrm{m}$ & $5 / 8$ & $229 \pm 24$ & $0.90 \pm 0.01$ & $0.91 \pm 0.01$ & $0.20 \pm 0.08$ \\
ORL 3 & $4-11 \mu \mathrm{m}$ & $9 / 9$ & $182 \pm 4$ & $0.95 \pm 0.01$ & $0.97 \pm 0.01$ & $0.10 \pm 0.02$ \\
& $63-90 \mu \mathrm{m}$ & $10 / 16$ & $225 \pm 13$ & $0.94 \pm 0.01$ & $0.94 \pm 0.01$ & $0.09 \pm 0.02$ \\
ORL 4 & $4-11 \mu \mathrm{m}$ & $8 / 9$ & $175 \pm 4$ & $0.95 \pm 0.01$ & $0.98 \pm 0.01$ & $0.08 \pm 0.01$ \\
& $63-90 \mu \mathrm{m}$ & $11 / 16$ & $181 \pm 10$ & $0.94 \pm 0.01$ & $0.94 \pm 0.01$ & $0.15 \pm 0.06$ \\
ORL 5 & $4-11 \mu \mathrm{m}$ & $7 / 7$ & $143 \pm 3$ & $0.97 \pm 0.01$ & $0.98 \pm 0.01$ & $0.02 \pm 0.02$ \\
& $4-11 \mu \mathrm{m} *$ & $7 / 7^{*}$ & $140 \pm 5$ & $0.98 \pm 0.01$ & $0.95 \pm 0.01$ & $0.33 \pm 0.23$ \\
& $63-90 \mu \mathrm{m}$ & $10 / 14$ & $180 \pm 10$ & $0.96 \pm 0.01$ & $0.96 \pm 0.01$ & $0.05 \pm 0.02$ \\
ORL 6 & $4-11 \mu \mathrm{m}$ & $7 / 7$ & $102 \pm 2$ & $0.98 \pm 0.01$ & $0.96 \pm 0.01$ & $0.01 \pm 0.04$ \\
& $4-11 \mu \mathrm{m} *$ & $7 / 7^{*}$ & $95 \pm 3$ & $0.97 \pm 0.01$ & $0.96 \pm 0.02$ & $0.10 \pm 0.07$ \\
ORL 7 & $63-90 \mu \mathrm{m}$ & $13 / 13$ & $133 \pm 7$ & $0.96 \pm 0.01$ & $0.95 \pm 0.01$ & $0.07 \pm 0.01$ \\
& $4-11 \mu \mathrm{m}$ & $9 / 9$ & $42.0 \pm 0.5$ & $1.01 \pm 0.01$ & $1.00 \pm 0.01$ & $0.07 \pm 0.03$ \\
& $4-11 \mu \mathrm{m} *$ & $7 / 7^{*}$ & $41.7 \pm 1.0$ & $0.98 \pm 0.02$ & $1.00 \pm 0.01$ & $0.04 \pm 0.03$ \\
ORL 8 & $63-90 \mu \mathrm{m}$ & $13 / 13$ & $36.3 \pm 1.8$ & $0.96 \pm 0.01$ & $0.97 \pm 0.01$ & $0.09 \pm 0.01$ \\
& $4-11 \mu \mathrm{m}$ & $9 / 9$ & $28.2 \pm 0.3$ & $1.00 \pm 0.01$ & $0.99 \pm 0.01$ & $0.09 \pm 0.03$ \\
& $4-11 \mu \mathrm{m} *$ & $7 / 7^{*}$ & $29.1 \pm 0.3$ & $0.99 \pm 0.02$ & $0.98 \pm 0.02$ & $0.18 \pm 0.02$ \\
& $63-90 \mu \mathrm{m}$ & $13 / 13$ & $28.8 \pm 1.1$ & $0.95 \pm 0.01$ & $0.97 \pm 0.01$ & $0.11 \pm 0.01$ \\
\hline
\end{tabular}




\begin{tabular}{|c|c|c|c|c|c|c|c|c|c|c|c|}
\hline $\begin{array}{l}\text { SAMPLE } \\
(4-11 \mu \mathrm{m})\end{array}$ & $\begin{array}{c}\text { Grain } \\
\text { size }\end{array}$ & $\begin{array}{c}\text { Depth } \\
\text { (cm) }\end{array}$ & $\begin{array}{c}\begin{array}{c}\text { Equivalent } \\
\text { dose } \\
(G y)\end{array} \\
\end{array}$ & $\begin{array}{l}\text { Ra-226 } \\
(\mathrm{Bq} / \mathbf{k g})\end{array}$ & $\begin{array}{l}\text { Th-232 } \\
(\mathrm{Bq} / \mathrm{kg})\end{array}$ & $\begin{array}{c}\mathrm{K}-40 \\
(\mathrm{~Bq} / \mathrm{kg})\end{array}$ & $\begin{array}{c}\text { Water } \\
\text { Content } \\
(\%) \\
\end{array}$ & $\begin{array}{c}\text { Anual } \\
\text { Dose } \\
\text { (Gy/Ka) }\end{array}$ & $\begin{array}{c}\text { Age (Ka) } \\
\text { Total error }\end{array}$ & $\begin{array}{c}\text { Random } \\
\text { Error } \\
(\%) \\
\end{array}$ & $\begin{array}{c}\text { Systematic } \\
\text { error } \\
(\%) \\
\end{array}$ \\
\hline \multirow[t]{2}{*}{ ORL 1} & $4-11 \mu \mathrm{m}$ & 965 & $292 \pm 10$ & $32.4 \pm 0.9$ & $35.6 \pm 0.3$ & $406 \pm 4$ & 20 & $2.63 \pm 0.03$ & $111 \pm 13$ & 3.6 & 11.1 \\
\hline & $63-90 \mu \mathrm{m}$ & & $347 \pm 38$ & & & & & $2.18 \pm 0.02$ & $159 \pm 23$ & 11 & 9.2 \\
\hline \multirow[t]{2}{*}{ ORL 2} & $4-11 \mu \mathrm{m}$ & 700 & $196 \pm 4$ & $31.9 \pm 0.6$ & $38.6 \pm 0.4$ & $456 \pm 7$ & 15 & $2.98 \pm 0.04$ & $65.8 \pm 6.6$ & 2.4 & 9.8 \\
\hline & $63-90 \mu \mathrm{m}$ & & $229 \pm 24$ & & & & & $2.49 \pm 0.02$ & $91.9 \pm 12.1$ & 10.5 & 7.9 \\
\hline \multirow[t]{2}{*}{ ORL 3} & $4-11 \mu \mathrm{m}$ & 600 & $182 \pm 4$ & $37.0 \pm 0.6$ & $38.2 \pm 0.3$ & $471 \pm 7$ & 10 & $3.31 \pm 0.04$ & $55.0 \pm 5.6$ & 2.5 & 9.9 \\
\hline & $63-90 \mu \mathrm{m}$ & & $225 \pm 13$ & & & & & $2.76 \pm 0.02$ & $81.4 \pm 8.0$ & 5.8 & 7.9 \\
\hline \multirow[t]{2}{*}{ ORL 4} & $4-11 \mu \mathrm{m}$ & 500 & $175 \pm 4$ & $32.1 \pm 0.4$ & $36.0 \pm 0.4$ & $444 \pm 7$ & 10 & $3.07 \pm 0.04$ & $57.0 \pm 5.2$ & 2.6 & 8.8 \\
\hline & $63-90 \mu \mathrm{m}$ & & $181 \pm 10$ & & & & & $2.57 \pm 0.02$ & $70.4 \pm 6.1$ & 5.6 & 6.7 \\
\hline \multirow[t]{2}{*}{ ORL 5} & $4-11 \mu \mathrm{m}$ & 400 & $143 \pm 3$ & $34.4 \pm 0.4$ & $37.1 \pm 0.3$ & $462 \pm 6$ & 10 & $3.22 \pm 0.04$ & $44.4 \pm 4.0$ & 2.4 & 8.8 \\
\hline & $63-90 \mu \mathrm{m}$ & & $180 \pm 10$ & & & & & $2.70 \pm 0.02$ & $66.7 \pm 5.8$ & 5.6 & 6.7 \\
\hline \multirow[t]{2}{*}{ ORL 6} & $4-11 \mu \mathrm{m}$ & 300 & $102 \pm 2$ & $37.4 \pm 0.5$ & $42.6 \pm 0.3$ & $546 \pm 7$ & 10 & $3.69 \pm 0.04$ & $27.7 \pm 2.5$ & 2.3 & 8.7 \\
\hline & $63-90 \mu \mathrm{m}$ & & $133 \pm 7$ & & & & & $3.10 \pm 0.02$ & $43.0 \pm 3.7$ & 5.3 & 6.7 \\
\hline \multirow[t]{2}{*}{ ORL 7} & $4-11 \mu \mathrm{m}$ & 180 & $42.0 \pm 0.5$ & $35.7 \pm 0.6$ & $34.9 \pm 0.4$ & $481 \pm 7$ & 10 & $3.39 \pm 0.04$ & $12.7 \pm 1.1$ & 1.7 & 8.6 \\
\hline & $63-90 \mu \mathrm{m}$ & & $36.3 \pm 1.8$ & & & & & $2.78 \pm 0.02$ & $13.1 \pm 1.1$ & 5.0 & 6.6 \\
\hline \multirow[t]{2}{*}{ ORL 8} & $4-11 \mu \mathrm{m}$ & 150 & $28.2 \pm 0.3$ & $34.8 \pm 0.7$ & $35.7 \pm 0.2$ & $476 \pm 6$ & 10 & $3.29 \pm 0.04$ & $8.6 \pm 0.7$ & 1.6 & 8.6 \\
\hline & $63-90 \mu \mathrm{m}$ & & $28.8 \pm 1.1$ & & & & & $2.77 \pm 0.02$ & $10.4 \pm 0.8$ & 3.9 & 6.6 \\
\hline
\end{tabular}

